\title{
Microwave-Assisted Palladium-Catalyzed Cross-Coupling Reactions: Generation of Carbon-Carbon Bond
}

\author{
Kifah S. M. Salih ${ }^{1, *(1)}$ and Younis Baqi ${ }^{2, *}$ (1) \\ 1 Department of Chemistry and Earth Sciences, College of Arts and Sciences, Qatar University, \\ P.O. Box 2713 Doha, Qatar \\ 2 Department of Chemistry, College of Science, Sultan Qaboos University, P.O. Box 36, Muscat 123, Oman \\ * Correspondence: ksalih@qu.edu.qa (K.S.M.S.); baqi@squ.edu.om (Y.B.); \\ Tel.: +974-4403-7552 (K.S.M.S.); +968-2414-1473 (Y.B.)
}

Received: 1 November 2019; Accepted: 16 December 2019; Published: 18 December 2019

check for updates

\begin{abstract}
Cross-coupling reactions furnishing carbon-carbon $(\mathrm{C}-\mathrm{C})$ bond is one of the most challenging tasks in organic syntheses. The early developed reaction protocols by Negishi, Heck, Kumada, Sonogashira, Stille, Suzuki, and Hiyama, utilizing palladium or its salts as catalysis have, for decades, attracted and inspired researchers affiliated with academia and industry. Tremendous efforts have been paid to develop and achieve more sustainable reaction conditions, such as the reduction in energy consumption by applying the microwave irradiation technique. Chemical reactions under controlled microwave conditions dramatically reduce the reaction time and therefore resulting in increase in the yield of the desired product by minimizing the formation of side products. In this review, we mainly focus on the recent advances and applications of palladium catalyzed cross-coupling carbon-carbon bond formation under microwave technology.
\end{abstract}

Keywords: cross-coupling reaction; $\mathrm{C}-\mathrm{C}$ bond formation; $\mathrm{Pd}$ catalysts; microwave

\section{Introduction}

The formation of carbon-carbon $(\mathrm{C}-\mathrm{C})$ bond through cross-coupling reactions represents as one of the most powerful tools in synthetic organic chemistry, therefore many attempts to develop new procedures featuring the $\mathrm{C}-\mathrm{C}$ bind formation are listed in the literature. The early reaction attempts go back in the history, precisely to the mid of the ninetieth century, were Charles Adolphe Wurtz was testing the effects of sodium metal (Na) on $\mathrm{C}-\mathrm{C}$ bond formation (Wurtz reaction, 1855), nine years later, this reaction was modified by Wilhelm Rudolph Fittig (Wurtz-Fittig reaction, 1864). In the beginning of the twentieth century, Fritz Ullmann was the first to report the use of transition metal element to form a C-C bond, Ullmann reaction 1901, followed by Cadiot-Chodkiewicz coupling in 1957, Castro-Stephens coupling in 1963, and Corey-House synthesis in 1967. All these reactions were performed in the presence of catalytic amount of cupper $(\mathrm{Cu})$. In the 1970s a breakthrough was achieved when palladium (Pd) was introduced as one of the most powerful catalysts in the $\mathrm{C}-\mathrm{C}$ bond formation. The developed reaction conditions were later on accredited and listed as named organic reactions, such as Kumada coupling (1972), Heck reaction (1972), Sonogashira coupling (1975), Negishi coupling (1977), Stille coupling (1978), Suzuki reaction (1979), Hiyama coupling (1988), and most recently Liebeskind-Srogl coupling (2000). Broad selections of ligands were tested and several catalyst systems have been invented, resulting in a large variety of new synthesized organic molecules. Additionally, many heterogenized palladium complexes and supported zerovalent palladium nanoparticles were frequently pursued for more sustainable recycling purposes [1,2]. Palladium-catalyzed cross-coupling reaction 
becomes widely commonplace in synthesis of fine chemicals, complex and functionalized structures and pharmaceutical intermediates. In 2010, Nobel Prize in Chemistry was awarded to Heck, Negishi, and Suzuki for their fundamental achievements in organic chemistry utilizing palladium catalysts.

Although cross-coupling reactions are routinely used in chemical synthesis, they display some limitations, which are mainly because of the high cost of palladium species, to some extend high cost of the ligand used, and the isolated products from cross-coupling reactions predominantly retain palladium. The cost issue will be ruled out in case of reducing the catalyst loading to $100 \mathrm{~mol} \mathrm{ppm}$, while reaching $10 \mathrm{~mol} \mathrm{ppm}$ will eliminate the concern of toxicity [3]. The reactivity trend of aryl halides in cross-coupling reactions is as follows: aryl iodide $>$ aryl bromide $>$ aryl chloride $>$ aryl fluoride. Thus, an efficient catalyst should transform the low-reactive substrates into products under mild reaction conditions.

The use of microwave irradiation heating rather than conventional heating systems fulfils the requirement of green chemistry through reducing the time of slow thermal reactions from several hours and in some cases from days to less than one hour reaction time, which usually last for minutes with significant energy savings, in addition to boost up the yield and bring down the level of side reactions $[4,5]$.

This paper highlights the recent advances and applications of palladium-catalyzed cross-coupling $\mathrm{C}-\mathrm{C}$ bond formation under controlled microwave irradiation technology. It covers the most recent protocols, whereas some earlier examples can be found briefly in previous literatures [6-8]. Furthermore, priority is given to protocols bearing transformation of wide-range of substrates, emphasizing on their utility and restrictions to simplify the further development of this attractive area of research.

\section{Palladium-Catalyzed Cross-Coupling Reactions under Microwave Irradiation}

\subsection{Heck Cross-Coupling Reaction}

In the early 1970s, both Heck [9] and Mizoroki [10] have separately reported the use of palladium to catalyze arylation reaction of olefins. Nowadays, this cross-coupling reaction is mostly recognized as the Heck reaction, which is considered as one of the most powerful method to substitute alkenes [11].

Usually, Heck reaction takes place through the generation of zerovalent palladium species as an active catalyst (Scheme 1 (a)). Oxidative addition step take place in which palladium(0) inserts itself in the aryl to halide bond, affording palladium(II) complex (b). Palladium consecutively forms a $\pi$ complex with the alkene (c), insertion of alkene in the palladium-carbon bond (d), and then beta-hydride elimination leads to the formation of a new palladium-alkene $\pi$ complex (e). Reductive elimination occurs as a final step giving the coupling product $(\mathbf{f})$ and releasing the active $\operatorname{Pd}(0)$ catalyst, after abstracting the halohalide (HX). The reaction is highly stereoselective in nature and proceeds smoothly in the presence of a base. A large number of research and review articles, covering the arts in Heck reaction, have been recently published [12]. 


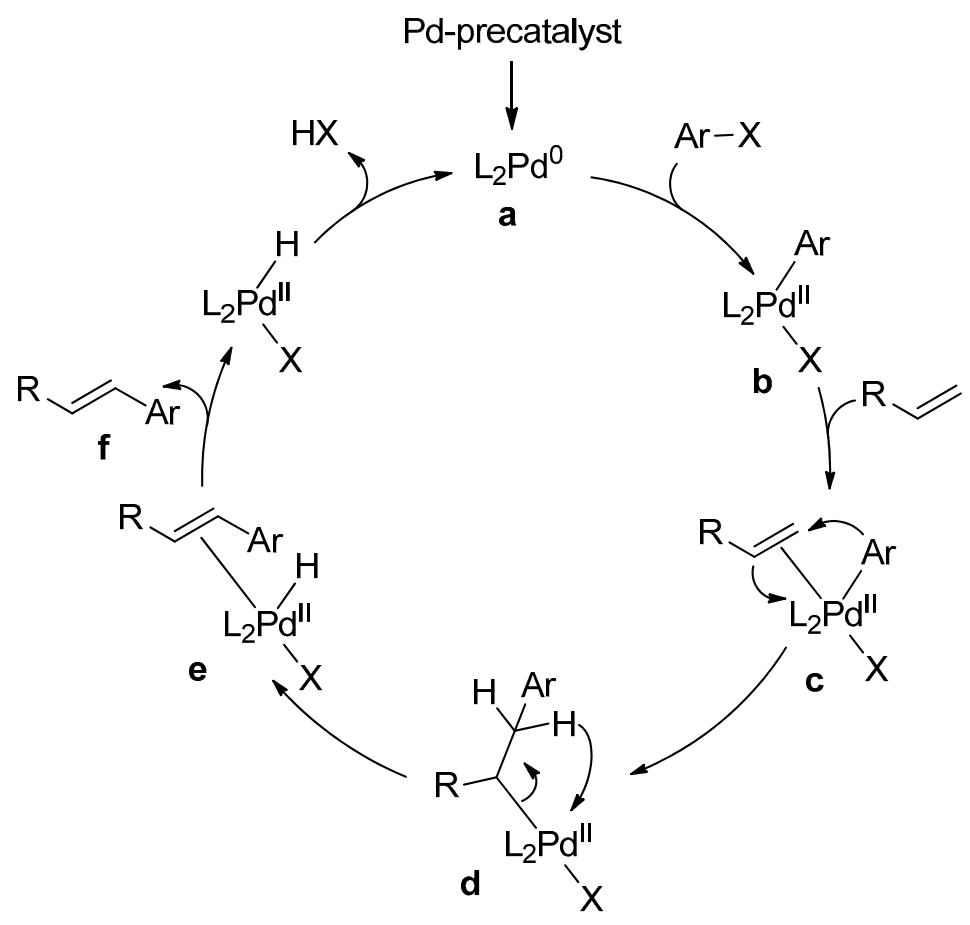

Scheme 1. Overall catalytic cycle for the Heck olefination reaction.

Heck reactions could proceed via two different routes, neutral or cationic [13]: the cationic pathway using bidentate phosphines and 1,10-phenanthroline derivatives gives rise to $\alpha$-arylation of terminal olefins (internal arylation) under electronically controlled coordination-insertion step, Scheme 2. Microwave heating was demonstrated to be beneficial in activation of aryl chlorides [14] or triflates [15] toward highly regioselective internal Heck arylation, in the presence of $\mathrm{Pd}(\mathrm{OAc})_{2}$ as a precatalyst with bidentate phosphine ligands (DPPF or DPPP). Conversely, $\beta$-arylation is promoted in the neutral pathway conditions out of sterical reasons.

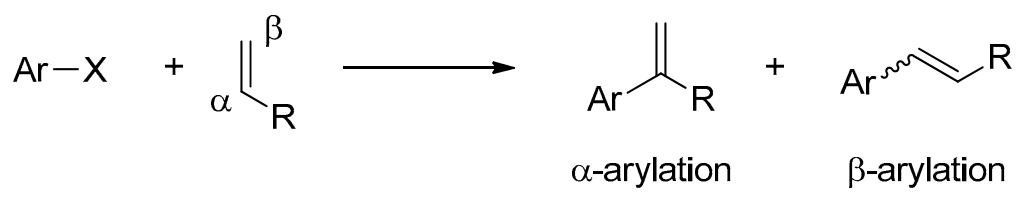

Scheme 2. Possible products from Heck arylation of olefins.

Larhed and coworkers have reported palladium-catalyzed selective terminal $\beta$-arylation of $n$-butyl vinyl ether with a series of electronically and sterically different aryl chlorides. Almost moderate yields were reached, when employing Herrmann's palladacycle, monodentate $\left[\left(t-\mathrm{Bu}_{3}\right) \mathrm{PH}\right] \mathrm{BF}_{4}$ pre-ligand to release $\mathrm{P}(t-\mathrm{Bu})_{3}$ and $\mathrm{Cy}_{2} \mathrm{NMe}$ as a base in aqueous DMF or polyethylene glycol 200 (PEG-200) under microwave irradiation. The selectivity for liner-product in PEG-200 was observed to be slightly higher than in aqueous DMF, Scheme 3 [16].

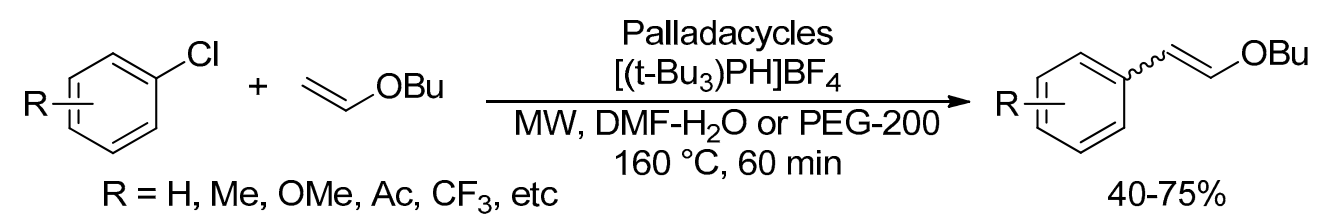

Scheme 3. Microwave-promoted Heck olefination of aryl halides using $\operatorname{Pd}(\mathrm{OAc})_{2}$. 
Several methodologies have been reported for Heck reaction under microwave conditions, such as the use of ionic liquids, phosphine ligands [17], supported catalysts [18] or Mg-Al layered double hydroxides (LDH) [19]. The latter revealed high turnover numbers in Heck olefination of various substituted aryl chlorides (Scheme 4). This activity was attributed that LDH stabilizes the nanopalladium particles and provides adequate electron density to the anchored zerovalent palladium species, as a result, enabling the oxidative addition step of the deactivated electron-rich chloroarenes.

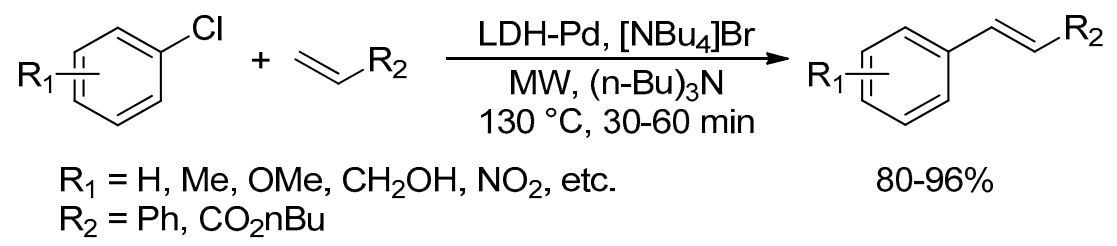

Scheme 4. LDH-Pd catalyzed Heck olefination of chloroarenes.

The employment of ionic liquids, as nonvolatile solvent at room-temperature, has attracted considerable attention in chemistry. Ionic liquids are promptly heated without any substantial pressure build-up, as they interact very efficiently with the microwave [20]. Xie et al. have used 1-octanyl-3-methylimidazolium tetrafluoroborate, $\left[\mathrm{OMIm}_{\mathrm{B}} \mathrm{BF}_{4}\right.$, in a solution of aryl halides, butyl acrylate, $(n-\mathrm{Bu})_{3} \mathrm{~N}$ and $3 \mathrm{~mol} \% \mathrm{Pd} / \mathrm{C}$. Aryl halides screening revealed that aryl iodide to proceed in higher yield compared to aryl-bromides or -chlorides, while the presence of a substituent in ortho-position to the halogen led to lower outcome, this is probably due to the steric effect. Aryl bromides bearing electron-withdrawing groups found to be more reactive and gave higher yields than those having an electron-donating groups, Scheme 5 [21].

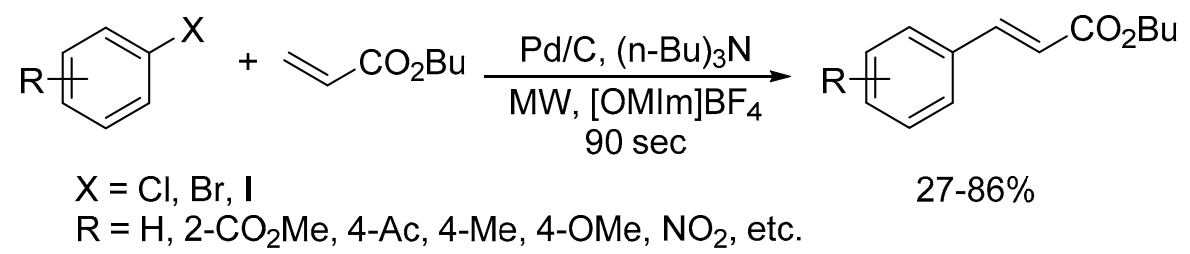

Scheme 5. Pd/C catalyzed Heck cross-coupling reaction.

Heck reaction was developed in several approaches including synthesis of natural products, heterocycles and bioactive molecules. Selection of biologically active 4-aryl-3-alkenyl-substituted quinolin-2 $(1 H)$-ones have been synthesized in Heck reaction using commercially available intermediates. The vinylation of 3-bromoquinolin-2(1H)-one derivatives with ethyl acrylate was investigated under microwave irradiation. The optimal reaction conditions were accomplished using $3 \mathrm{~mol} \%$ of tetrakis(triphenylphosphine) palladium(0) and 3 equiv. of triethylamine as base in DMF (Scheme 6). Full conversions to products were achieved in high yields within $40-45 \mathrm{~min}$, in less than $5 \%$ of debrominated quinolinones being produced as byproducts [22].<smiles>[R]c1ccc2c(c1)c([R])c(Br)c(=O)n2[R2]</smiles>

$\mathrm{R}_{1}=\mathrm{H}, \mathrm{CF}_{3} ; \mathrm{R}_{2}=\mathrm{H}, \mathrm{Me}$

$\mathrm{R}_{3}=\mathrm{Ph}, 3-\mathrm{Cl}-5-\mathrm{MeOC}_{6} \mathrm{H}_{3}$

$81-90 \%$

Scheme 6. Synthesis of 4-aryl-3-alkenyl-substituted quinolin-2(1H)-ones via Heck vinylation. 
A simple modification to the classical Heck reaction under microwave irradiation afforded valuable conversions of aryl halides with terminal olefins using $0.05 \mathrm{~mol} \%$ of palladium acetate $\left(\mathrm{Pd}(\mathrm{OAc})_{2}\right)$. The reaction mixture was adsorbed on neutral alumina and irradiated at $300 \mathrm{~W}$ for 20-25 min under solvent- and ligand-free conditions, Scheme 7 . Both aryl bromides and iodides were converted into high yields, whereas the efficiency of aryl chlorides was found to be very low even after applying a double amount of the catalyst. Moreover, electron-deficient aryl halides were more reactive than the electron-rich ones [23].

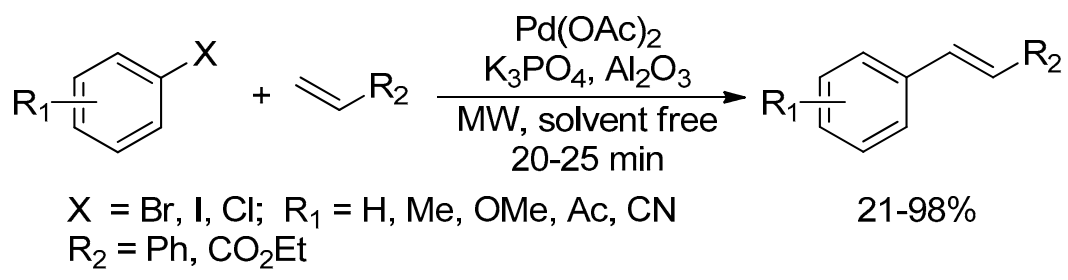

Scheme 7. Microwave-promoted Heck olefination of aryl halides using $\operatorname{Pd}(\mathrm{OAc})_{2}$.

Palladium nanoparticles supported on graphene $(\mathrm{Pd} / \mathrm{G})$ were fabricated by microwave-assisted chemical reduction of the aqueous mixture of palladium nitrate and dispersed graphite oxide sheets. The developed heterogeneous $\mathrm{Pd} / \mathrm{G}$ catalyst was investigated in $\mathrm{C}-\mathrm{C}$ cross-coupling reactions (Heck and Suzuki). The performance of $\mathrm{Pd} / \mathrm{G}$ demonstrated high catalytic activity in opposite to the widely used palladium supported on charcoal $(\mathrm{Pd} / \mathrm{C})$ catalyst, this was attributed to high stability of $\mathrm{Pd}$ particles on the supported graphene. $\mathrm{Pd} / \mathrm{G}$ found to be useful heterogeneous catalyst for Heck cross-coupling reaction between aryl bromide and styrene derivatives using $0.3 \mathrm{~mol} \%$ of the catalyst in the presence of potassium carbonate in aqueous ethanol under microwave heating for $10 \mathrm{~min}$, Scheme 8 . While aryl chlorides were failed to be converted [24].

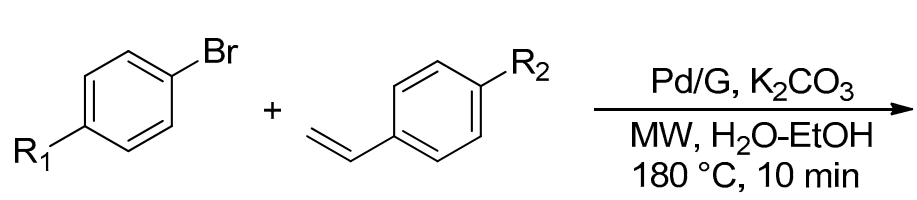

$\mathrm{R}_{1}=\mathrm{H}, \mathrm{CHO}, \mathrm{CO}_{2} \mathrm{H}, \mathrm{OMe}, \mathrm{CN}$ $\mathrm{R}_{2}=\mathrm{H}, \mathrm{Cl}, \mathrm{tBu}$<smiles>[R]c1ccc(/C=C/c2ccc([R])cc2)cc1</smiles>

$84-97 \%$

Scheme 8. Pd/G catalyzed Heck olefination of aryl bromides and styrenes.

Recently, there has been a significant amount of research on the use of natural-based materials such as cyclodextrins [25], cellulose [26] and cucurbit [7] uril [27], to support Pd nanoparticles, for their unique and potentially useful features. The Pd-loaded materials showed good conversion activity in Heck cross-coupling reactions under irradiation condition. Furthermore, monosaccharides are widely available biomolecules and attempt to develop greener and economical chemical reactions. Monosaccharides are used for its several advantages, such as the cost-effectiveness, for the coordination with metals, and as a reducing agent for the stabilization of the catalytically active nanoparticles [28]. Jain's group has studied the potential for the addition of $D$-glucosamine to Heck coupling reactions, exploring the possibility of replacing organophosphines. After optimization of the reaction conditions, the feasibility was assessed for a selection of aryl and heteroaryl iodides and bromides with styrene. Therefore, substituted trans-stilbenes and heteroaryl olefins were obtained in the presence of $0.1 \mathrm{~mol} \%$ of $\mathrm{Pd}(\mathrm{OAc})_{2}, D$-glucosamine (1 equiv.), and $\mathrm{K}_{2}\left(\mathrm{CO}_{3}\right)_{2}$ (3 equiv.) in aqueous DMF under microwave heating for $60 \mathrm{~min}$. As usual, the yields resulting from conversion of aryl iodides are higher than aryl bromides. Aryl bearing at 4-position electron-withdrawing groups is found to be more reactive compared with electron-donating functions, Scheme 9 [29]. 


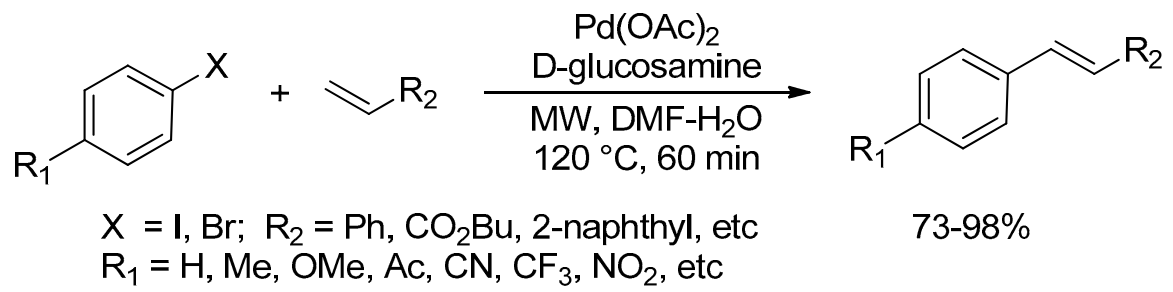

Scheme 9. Heck olefination of aryl halides using $\mathrm{Pd}(\mathrm{OAc})_{2}$ in the presence of $D$-glucosamine.

Under controlled microwave process, Larhed and coworkers have explored the scope and limitations of the base-free oxidative Heck reaction with arylboronic acids, employing $\mathrm{Pd}(\mathrm{OAc})_{2}$, dmphen (2,9-dimethyl-1,10-phenanthroline) as the regio-controlling ligand and with $p$-quinone or air as reoxidants of zerovalent palladium complex. The oxidative couplings of arylboronic acids with both electron-rich and electron-poor olefins were conducted smoothly and regioselectively, giving high yields even with disubstituted butyl methacrylate, sensitive acrolein, and a vinylboronate ester, Scheme 10 [30]. Likewise, palladium-catalyzed decarboxylative Heck reaction of 2,6-dimethoxybenzoic acid and methyl acrylate was recently reported as a proof of principle study under irradiation condition and using molecular oxygen as the oxidizing agent [31].

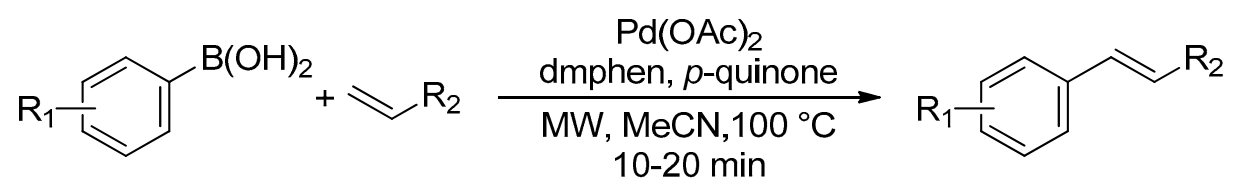

$\mathrm{R}_{1}=\mathrm{H}, \mathrm{Me}, \mathrm{OMe}, \mathrm{Ac}, \mathrm{CHO}, \mathrm{CF}_{3}$, etc

$\mathrm{R}_{2}=\mathrm{CO}_{2} \mathrm{Bu}, \mathrm{CHO}, \mathrm{CONMe}_{2}, \mathrm{SO}_{2} \mathrm{Ph}, \mathrm{Ph}, \mathrm{O}-\mathrm{t}-\mathrm{Bu}$, etc

$50-95 \%$

Scheme 10. Microwave-promoted Heck oxidative reaction of arylboronic acids with olefines.

\subsection{Sonogashira Cross-Coupling Reaction}

Sonogashira cross-coupling reaction has been developed in 1975 and since then proves to be as one of the very useful reaction implemented successfully in a wide variety of research active areas, including drug discovery and development, in the synthesis of heterocycles and natural products [32]. This reaction involves the coupling between an $\mathrm{sp}^{2}$ carbon of an aryl or vinyl halide (or pseudohalide) with a terminal sp hybridized carbon from an alkyne. Although, the reaction mechanism is fairly well established in the literature, it consists of two catalytic cycles and researchers mainly revolve around a palladium cycle. It is proposed that the reaction typically goes through zerovalent palladium species as an active catalyst. In the oxidative addition step, the insertion of palladium(0) into aryl halide bond delivers the palladium(II) complex (b). A side cycle supported by copper as a co-catalyst (CuX) develops the $\sigma$-alkynylcopper(I) organometallic reagent (g) for transmetalation step with complex $\mathbf{b}$. The $\sigma$-alkynylpalladium(II) intermediate $(\mathbf{h})$ is yielded afterward along with the active $\mathrm{Cu}$ species, which involves with alkyne substrate and base in second reaction sequence (Cu-cycle). Reductive elimination takes place eventually to afford the coupling product (i) and to regenerate the active $\operatorname{Pd}(0)$ catalyst, Scheme $11[33,34]$. 


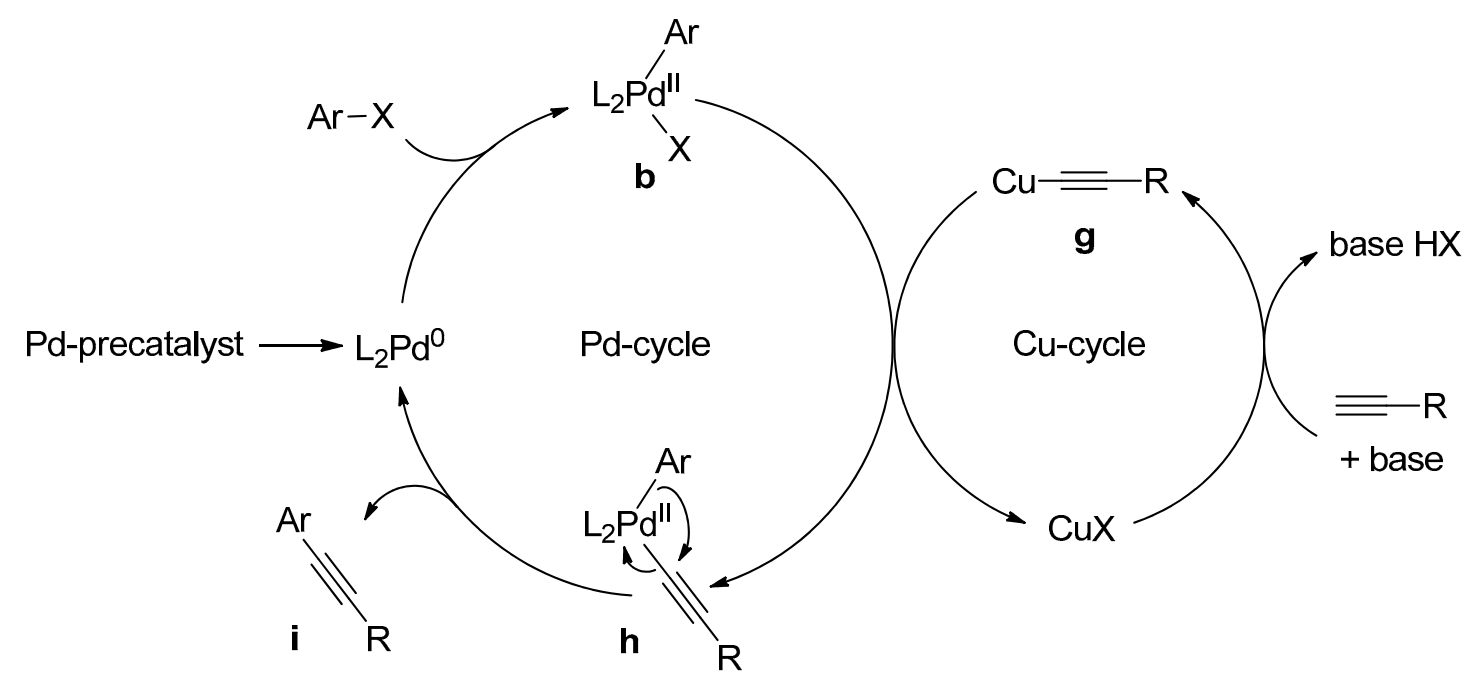

Scheme 11. Overall mechanism for the Pd/Cu-catalyzed Sonogashira cross-coupling reaction.

In a one-pot synthesis of indoles under microwave irradiation, Larock's group has reported the in situ alkynylation of $\mathrm{N}$-substituted/N,N-disubstituted 2-iodoaniline in typical Sonogashira coupling conditions. The scope of the reactions was demonstrated by electron-rich aryl acetylenes, using $\mathrm{PdCl}_{2}\left(\mathrm{PPh}_{3}\right)_{2}, \mathrm{CuI}$ and $\mathrm{Et}_{3} \mathrm{~N}$ at $60{ }^{\circ} \mathrm{C}$ for 20-30 min [35]. 5-Iodo-4-methoxy-2-pyridone derivatives reacted with terminal alkynes under microwave-enhanced Sonogashira conditions. The cross-coupling products have undergone sequential demethylation and furan annulation, furnishing 7-arylfuro[3,2-c]pyridin-4(5H)-ones in a one-pot reaction [36]. On the other hand, aryl bromides were cross-coupled with terminal alkynes under mild conditions in the presence of $\mathrm{PdCl}_{2}\left(\mathrm{PPh}_{3}\right)_{2}, \mathrm{CuI}$ and $\mathrm{Et}_{3} \mathrm{~N}$ under irradiation for $10 \mathrm{~min}$ (Scheme 12) [37].<smiles>[R]C#C[NH2+]N([R2])c1ccc([R3])cc1I</smiles>

$\mathrm{R}_{1}=\mathrm{H}, \mathrm{Me} ; \mathrm{R}_{2}=\mathrm{Me}, \mathrm{COCF}_{3}$ $\mathrm{R}_{3}=\mathrm{H}, \mathrm{Me}, \mathrm{CO}_{2} \mathrm{Me}$, $\mathrm{R}_{4}=\mathrm{Ph},\left(\mathrm{CH}_{2}\right)_{2} \mathrm{OH},\left(\mathrm{CH}_{2}\right)_{3} \mathrm{CN}$, 3-thienyl, 4- $\mathrm{MeOC}_{6} \mathrm{H}_{4}$, etc

1) $\mathrm{PdCl}_{2}\left(\mathrm{PPh}_{3}\right)_{2}, \mathrm{Cul}, \mathrm{Et}_{3} \mathrm{~N}$ 20-30 min 2) $\mathrm{Arl}, \mathrm{MeCN}, \mathrm{MW}, 90-100{ }^{\circ} \mathrm{C}$

Scheme 12. One-pot synthesis of indoles under microwave irradiation.

Pd-loaded multi-walled carbon nanotubes (Pd/MWCNT) have been used in alkynylation reactions in the absence of copper salts and phosphine ligands. Under microwave irradiation for $5 \mathrm{~min}$ at 135-160 ${ }^{\circ} \mathrm{C}$, the reaction of iodoarenes with 4-ethynyltoluene in a mixture of ethanol-water and potassium carbonate as base afforded the cross-coupled products in good yields. Notably, when piperidine (pip) is used instead of $\mathrm{K}_{2} \mathrm{CO}_{3}$ in ethanol, much poorer yields were reached for the reactants with electron-donating groups on the iodoarene moieties (Scheme 13). The catalyst revealed moderate leaching of $\mathrm{Pd}(1.1 \%)$ in the first use and is mentioned in at least five times of recycling, though recycling is not demonstrated [38]. Similarly, graphene-supported Pd nanoparticles (Pd/G) were reported for Sonogashira reaction of conversion of few electron-rich iodo-substrates with phenylacetylene under solvent-free microwave irradiation conditions for $40 \mathrm{~min}$ [39]. The substantial drawback of using these supported catalysts ( $\mathrm{Pd} / \mathrm{MWCNT}$ and $\mathrm{Pd} / \mathrm{G})$ is the conversion to the desired products is limited to the aryl iodides. This is probably due to the fact that Pd nanoparticles might be mainly buried in the supported frame. 


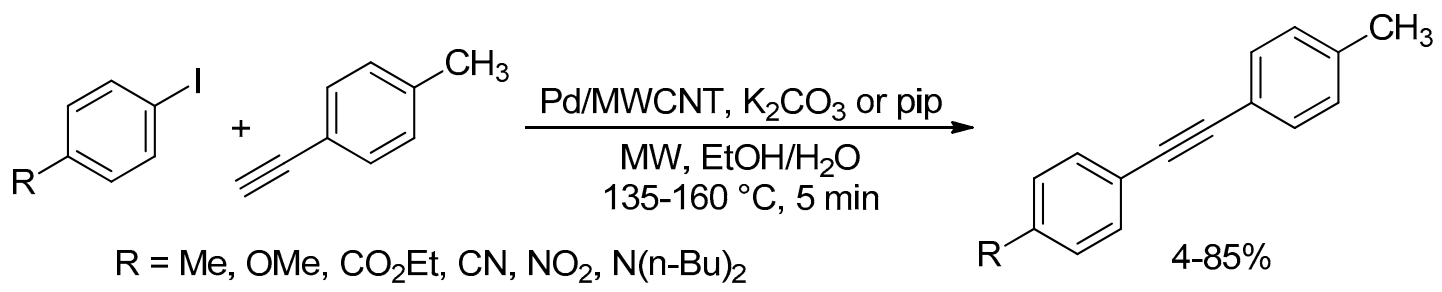

Scheme 13. Pd/MWCNT-catalyzed Sonogashira coupling reactions.

Sedelmeier et al. have reported the application of polyuria microencapsulated palladium catalyst (PdEnCat ${ }^{\mathrm{TM}}$ TPP30) in Sonogashira cross-coupling reactions promoted by microwave irradiation. Under the optimized reaction conditions, only aryl bromides and iodides reacted with a wide variety of terminal alkynes, giving rise to the corresponding coupling products in good to excellent yields. Both electron-rich and electron-deficient aryl halides were coupled under copper and inert atmosphere free-conditions in the presence of $\mathrm{DBU}$ in $\mathrm{MeCN}$ at $100-120^{\circ} \mathrm{C}$. The reactions have demonstrated a good level of functional group tolerance toward acetyl, alcohol, ester, chloro, amide, nitrile, and nitro groups (Scheme 14). Additionally, a number of functionalized enynes was also generated in good yields by conducting the reaction with a cis/trans-mixture of $\beta$-bromostyrene as a halide partner. Recycling the catalyst after simple filtration was investigated in the coupling reaction between 4-bromoacetophenone and phenylacetylene. A yield of $98 \%$ from the first use of the catalyst was dropped down to $92 \%$ in the sixth cycle. This minor loss in the catalytic activity states that the metal release from the encapsulated Pd-species is very slow [40].

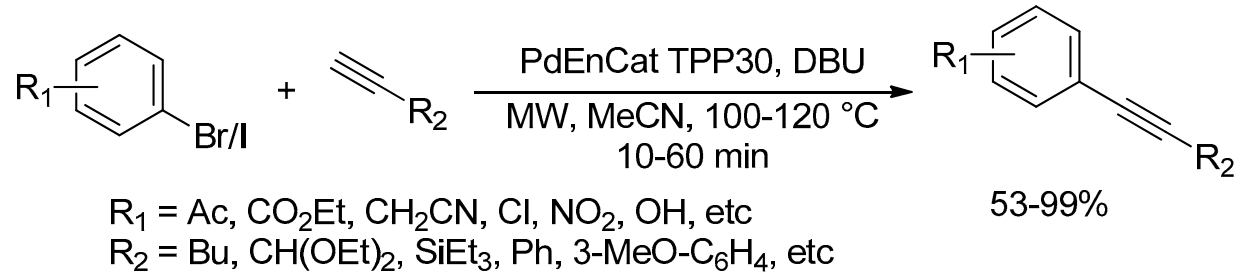

Scheme 14. PdEnCat TPP30-catalyzed Sonogashira coupling reaction.

Under solvent-free microwave irradiation conditions, Sonogashira reaction was described using palladium modified mesoporous materials and zeolites, such as Pd-MCM-41, Pd-Y, Pd-VSB-5, and Pd-SBA-15. For instance, various phenyl iodides, bearing bromo or chloro functionality, were coupled with phenylacetylene using Pd-MCM- 41 or Pd-Y in the presence of DBU as a base at $120^{\circ} \mathrm{C}$ in $40 \mathrm{~min}$ (Scheme 15) [41].

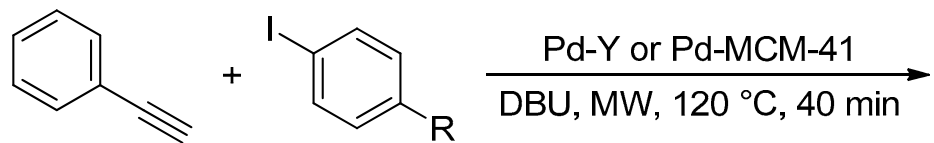

$\mathrm{R}=\mathrm{H}, \mathrm{Me}, \mathrm{Et}, \mathrm{OH}, \mathrm{OMe}, \mathrm{F}, \mathrm{Cl}, \mathrm{Br}, \mathrm{NO}_{2}$

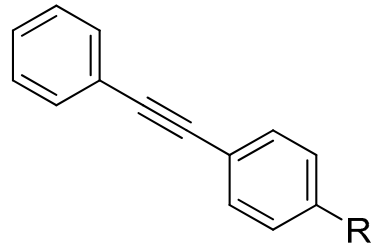

$4-93 \%$

Scheme 15. Pd-modified mesoporous materials catalyzed Sonogashira coupling reaction.

Bodke and coworkers have developed an access for the synthesis of 4-methyl-7-alkyl/aryl/heteroaryl alkynyl coumarins under microwave irradiation. In the presence of $\mathrm{PdCl}_{2}\left(\mathrm{PCy}_{3}\right)_{2}, \mathrm{TBAF} \cdot 3 \mathrm{H}_{2} \mathrm{O}$ and DMA as a solvent, the cross-coupling reaction of 4-methyl-7-nonafluorobutylsulfonyloxy coumarin with a selection of terminal alkynes was achieved (Scheme 16). The products were obtained in high yields with electron rich acetylenes, while slightly 
lesser yields were achieved with electron deficient alkynes in 18-33 min. Remarkably, nonaflates were showed to couple more efficiently than the analogous triflates, which generated the required product along with competing detriflated- and hydrolyzed-side products [42].

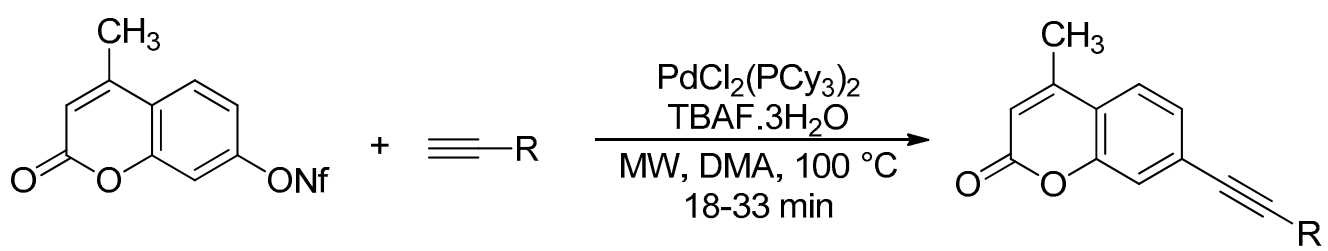

$\mathrm{R}=\mathrm{CH}_{2} \mathrm{OH}, \mathrm{CH}(\mathrm{OH}) \mathrm{CH}_{3}, \mathrm{Ph}, 4-\mathrm{MeOC}_{6} \mathrm{H}_{4}$, 4- $\mathrm{FC}_{6} \mathrm{H}_{4}, 4-(3-p y r i d y l) \mathrm{C}_{6} \mathrm{H}_{4}, 4-\mathrm{N}(\mathrm{Me})_{2} \mathrm{C}_{6} \mathrm{H}_{4}$, etc.

Scheme 16. Synthesis of 4-methyl-7-alkyl/aryl/heteroaryl alkynyl coumarins.

A method for the synthesis of 1-aryl-2-(trimethylsilyl)acetylene was recently developed using copper and palladium-catalyzed coupling of trimethylsilylacetylene and aryl bromides or iodides. Under microwave irradiation in acetonitrile and in the presence of triethylamine as a base. The desired products, bearing numerous functional groups, were obtained in good to excellent yields within 2-10 min. Aryl halides substituted on position-2 were coupled in slightly lesser yields, whereas, good results were achieved for heterocyclic aryl halides or naphthalene halides under same reaction conditions (Scheme 17) [43].

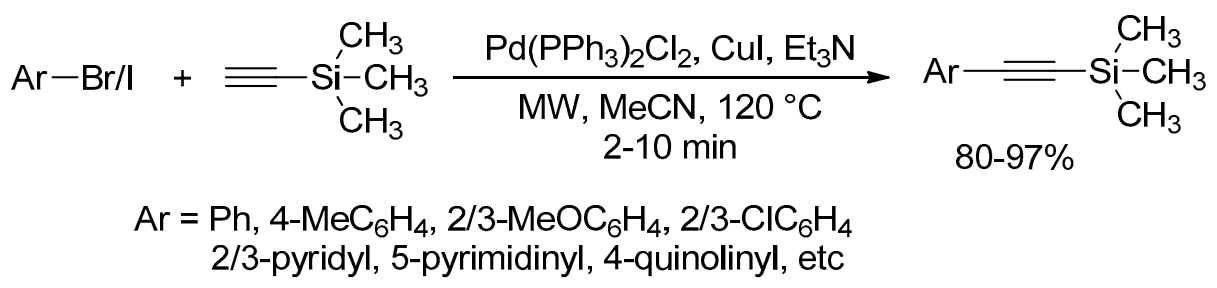

Scheme 17. Sonogashira reaction of aryl- or heteroaryl-halides with trimethylsilylacetylene.

Eventually, a limited number of homogenous palladium complexes [44,45] and supported palladium nanoparticles [46] were described for Sonogashira coupling reaction of aryl bromide and iodide with phenylacetylene under microwave reaction condition.

It is worth mentioning that the mechanism of copper-free Sonogashira reaction was earlier proposed as a monometallic mechanism [47]. However, a catalytic cycle proceeds through a tandem $\mathrm{Pd} / \mathrm{Pd}$ cycle comparable to the $\mathrm{Pd} / \mathrm{Cu}$ tandem variant (Scheme 11) was quite recently revealed, supported by considerable experimental and computational scrutiny [48].

\subsection{Suzuki Cross-Coupling Reaction}

The palladium-catalyzed Suzuki cross-coupling, developed in 1979, is by far one of the most explored reaction in organic chemistry to synthesize unsymmetrical biaryl derivatives. It is also known in numerous publications by the name Suzuki-Miyaura reaction. The reaction employs readily available substrates, arylhalide and organoboron compounds, and tolerates a selection of functional groups under mild reaction conditions. The stability of boronic acids to heat and water, in addition to ease of handling and separation of by-products from the reaction mixtures, makes the reaction widely applicable under homogeneous and heterogeneous conditions [49]. Typically, the cross-coupling reaction proceeds through the generation of zerovalent palladium species, Scheme 18. The active Pd-catalyst (a) is subjected to oxidative addition step by aryl halide, affording palladium(II) complex (b). The coupling partner, boronic acid, undergoes a transmetallation in the presence of base, giving the diarylpalladium(II) intermediate (j). Finally, the reductive elimination proceeds to give the coupling 
biaryls product $(\mathbf{k})$ and releasing the active $\mathrm{Pd}(0)$ catalyst. High catalyst loading is needed when aryl chlorides is used, because of the disfavored oxidative addition step raising from high $\mathrm{C}-\mathrm{Cl}$ bond strength compared with C-Br and C-I bonds [50]. Moreover, this overall catalytic cycle is almost functional in Stille, Negishi, Hiyama, Kumada, and decarboxylative cross-coupling reactions [51].

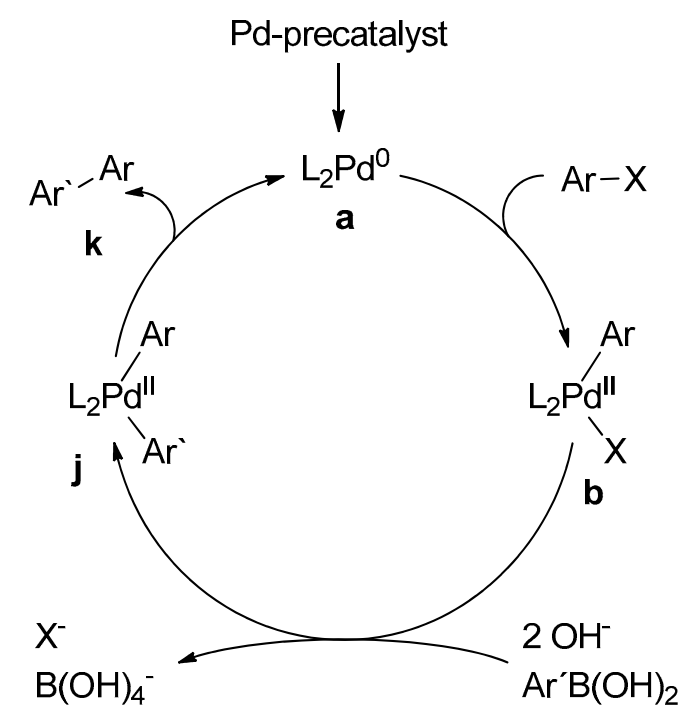

Scheme 18. Overall catalytic cycle for the Suzuki cross-coupling reaction.

Schotten's group has reported that palladium acetate catalyzes the cross-coupling reaction of poly(ethylene glycol) (PEG) ester of bromo-, iodo-, and triflate-para-substituted benzoates with aryl boronic acids in water under microwave irradiation for 2-4 min (Scheme 19). Under ligand free condition, high conversion of starting materials was observed and the produced polymeric support remains more stable than the one prepared under conventional thermal conditions, that induced ester bond cleavage [52]. Similarly, palladium acetate in low-loading $(0.4 \mathrm{~mol} \%)$ was used in cross-coupling reaction of aryl bromides with phenylboronic acid in water under microwave heating [53].

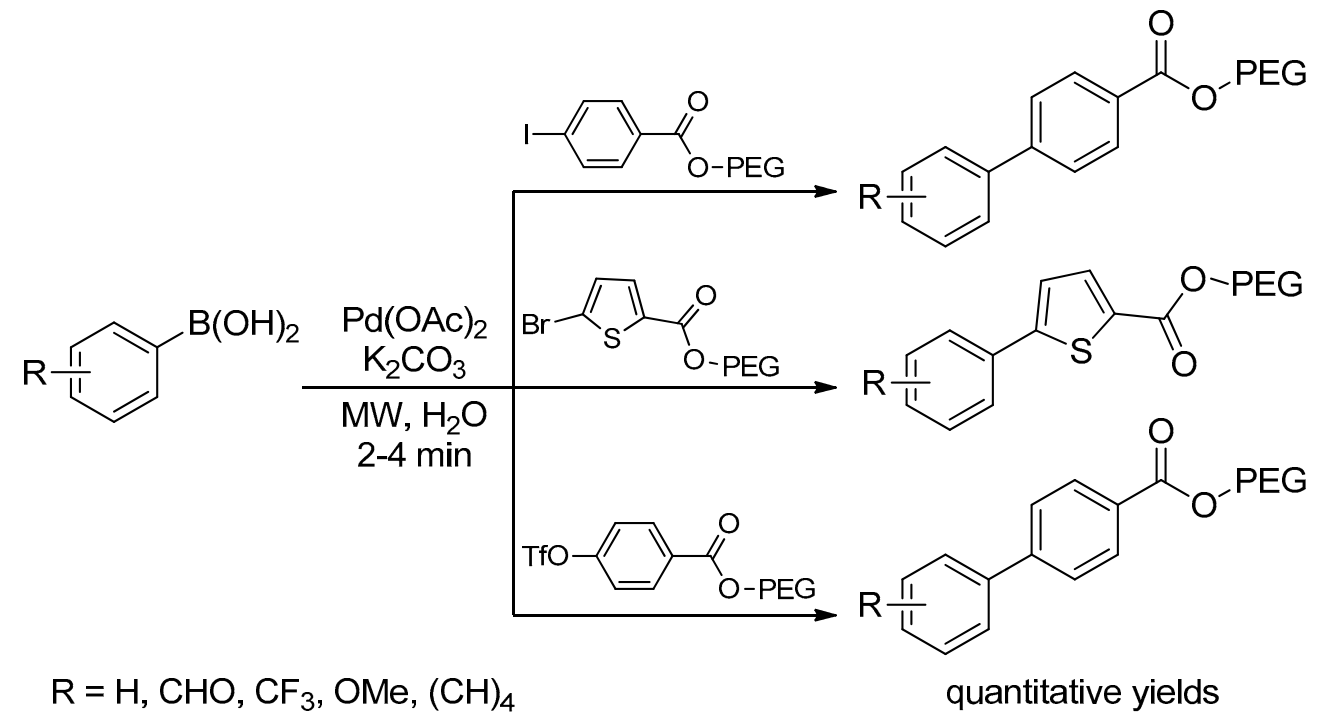

Scheme 19. Palladium(II) acetate catalyzes the Suzuki cross-coupling reaction.

The coupling of an arylboronic acid to a $\beta$-chloroalkyl/arylidene malonate in the presence of $\mathrm{K}_{2} \mathrm{CO}_{3}$ and $1 \mathrm{~mol} \%$ of the air-stable palladium catalyst, $\left[(t-\mathrm{Bu})_{2} \mathrm{P}(\mathrm{OH})\right]_{2} \mathrm{PdCl}_{2}$, under microwave irradiation affords $\beta$-aryl/alkylarylidene malonates, which were synthesized mainly upon Knoevenagel 
condensation. The mild reaction conditions allow a variety of arylboronic acids bearing electron-rich, electron-deficient, sterically demanding systems, amino and hydroxyl functionality to afford the products in good yields, Scheme 20 [54].<smiles></smiles>

$\mathrm{R}_{1}=\mathrm{H}, \mathrm{Me}, \mathrm{OMe}, \mathrm{CF}_{3}, \mathrm{Cl}, \mathrm{F}, \mathrm{NH}_{2}, \mathrm{NO}_{2}, \mathrm{OH}$ $\mathrm{R}_{2}=\mathrm{Me}, \mathrm{i}-\mathrm{Pr}, \mathrm{Ph}$<smiles>[R]C(Cl)=C(OCC)C(=O)OCC</smiles>

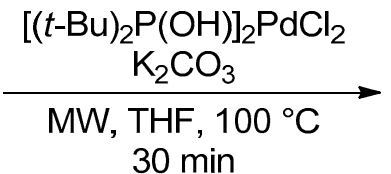
$30 \mathrm{~min}$

Scheme 20. Suzuki coupling reaction of arylboronic acids with $\beta$-chloroalkyl/arylidene malonates.

Zhu et al. have introduced aromatic group onto the bromotriazole acyclonucleoside derivative via Suzuki coupling reaction. The 5-aryltriazole acyclonucleosides featuring numerous aromatic groups on the triazole ring were synthesized using tetrakis(triphenylphosphine)palladium( $(0)$ in aqueous solution under microwave irradiation. Remarkably, the type of the used base significantly affects the reaction. Good to excellent yields were achieved when $\mathrm{K}_{2} \mathrm{CO}_{3}$ is employed and the coupling products were formed but in favor of intra-molecular cyclization of 5-bromo triazole derivatives. However, almost a quantitative yields of the coupling products were achieved when $\mathrm{Li}_{2} \mathrm{CO}_{3}$ is utilized, suppressing the cyclization of the starting material completely. The base behavior was justified to the formation of a $\mathrm{Li}^{+}$-complex with the side chain of 5-bromotriazole derivative, prohibiting the cyclization and consolidating the Suzuki coupling reactions, Scheme 21 [55].

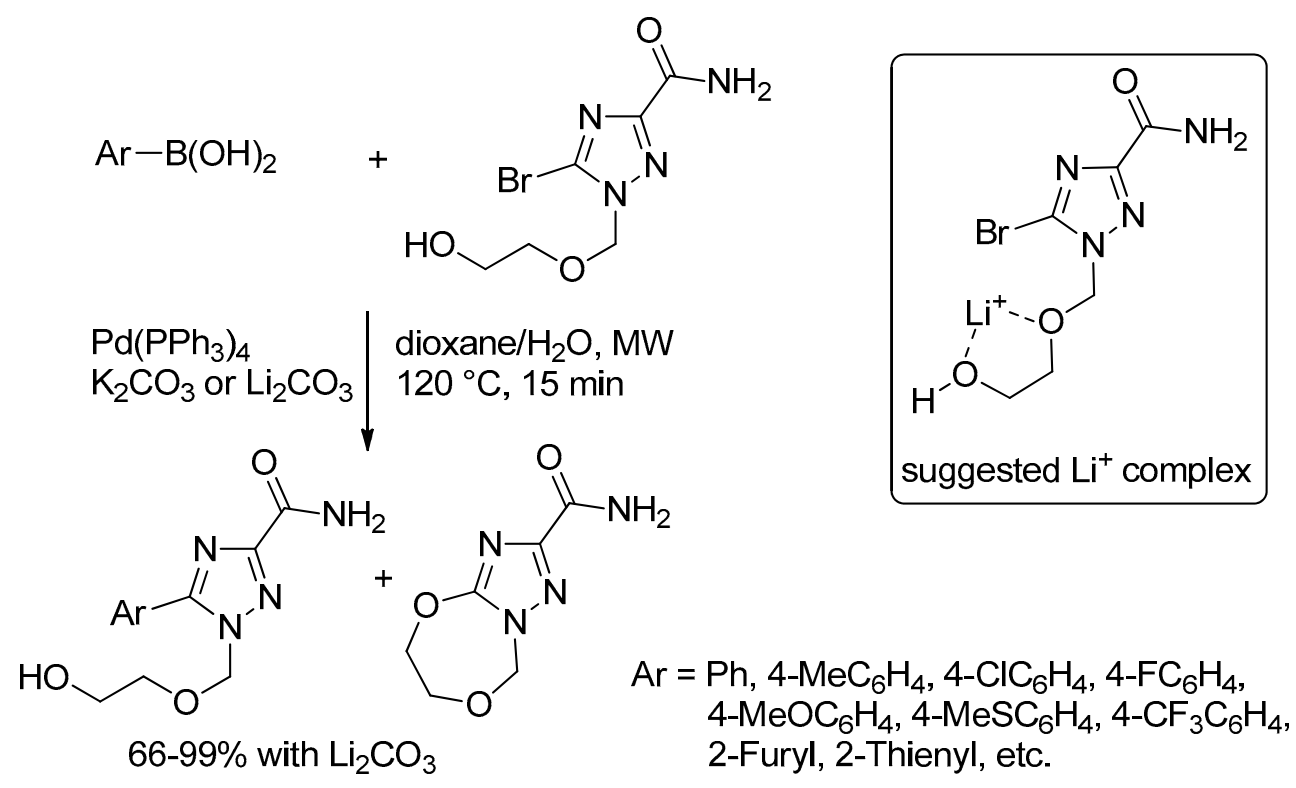

Scheme 21. Synthesis of 5-aryltriazole acyclonucleosides via Suzuki coupling reactions.

Solvent-free conditions have been frequently revealed in synthetic chemistry to reduce cost and amount of waste generated from side reactions. In non-solvent conditions, the conversions of solid or liquid aryl halides with various arylboronic acids to cross-coupled products were accomplished in high yields, using $1 \mathrm{~mol} \%$ of PEPPSI-iPr (pyridine-enhanced precatalyst preparation, stabilization, and initiation) and three equiv. of $\mathrm{K}_{2} \mathrm{CO}_{3}$ at $110{ }^{\circ} \mathrm{C}$ for 10 min under microwave irradiation (Scheme 22). To obtain full conversions, a good homogenization of all solid reactants in a mortar is necessary before charging them into the microwave reaction vial. This rapid methodology works smoothly with aryl 
bromides and iodides, while the presence of electron-withdrawing substituents on the less-reactive aryl chlorides is essential to obtain full conversion [56].

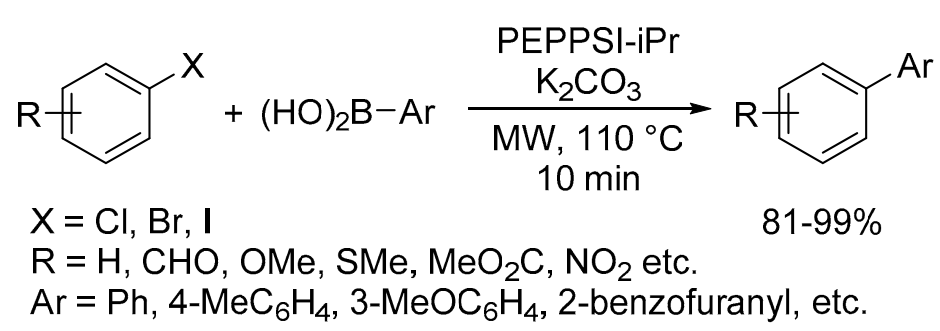

Scheme 22. Solvent-free PEPPSI-iPr-catalyzed Suzuki cross-coupling reactions.

A range of aryl bromides bearing electron-donating or electron-withdrawing substituents such as-Me, $-\mathrm{NH}_{2},-\mathrm{CO}_{2} \mathrm{H}$, - $\mathrm{NO}_{2}$, etc., were cross-coupled with phenylboronic acid in an open-vessel condition. One mole scale of reactants was used with $0.009 \mathrm{~mol} \%$ of palladium stock solution and $\mathrm{Na}_{2} \mathrm{CO}_{3}$ in aqueous ethanol under microwave irradiation, affording the biphenyl products in moderate to excellent yields, Scheme 23 [57].

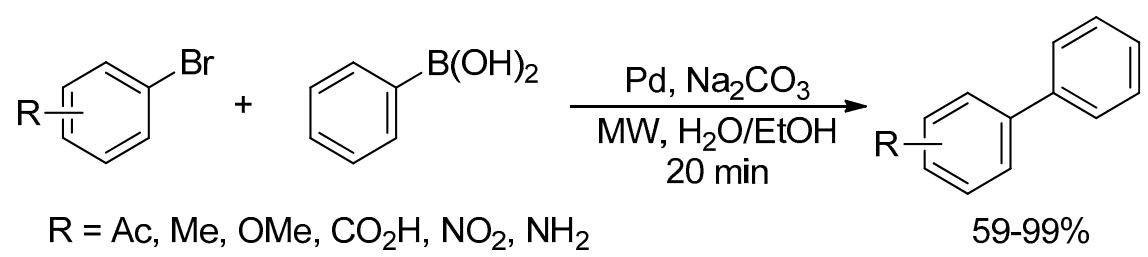

Scheme 23. Palladium-catalyzed Suzuki cross-coupling reactions.

The use of recyclable solid catalyst under microwave irradiation condition offers a series of advantages, including the direct recovery of both product and catalyst. Hence, homogeneous palladium catalysts or nanoparticles were doped, impregnated [58], or immobilized [59] on various supports to address the issues of separation. Solventless microwave-assisted Suzuki reaction of aryl halides and boronic acids on palladium-doped $\mathrm{KF} / \mathrm{Al}_{2} \mathrm{O}_{3}$ was first reported by Kabalka et al. [60]. The reaction performance was found to be insensitive to the substituents on the boronic acid and most efficient when aryl iodides are utilized (Scheme 24). Vinyl boronic acid or allylic halide were transformed smoothly to the cross-coupled products, whereas no reactions were observed when alkylboronic acid, vinyl halide, or alkyl halide were involved as reactants [61]. Although this transformation represented as a satisfactory work, the authors did not mention details on yield and Pd leaching after subsequent reuse of the doped catalyst. This protocol encountering two main limitations, the first one is that the cross-coupling does not proceed with aryl chloride, and the second limitation is that the $\mathrm{KF} / \mathrm{Al}_{2} \mathrm{O}_{3}$ sample needs to be exposed to ambient air for at least two weeks prior to use and in order to obtain good yields. This could be rationalized that the presence of high level of moisture accelerates the cross-coupling reactions.<smiles>[Y]C(Br)=[R]=C</smiles>

Scheme 24. Pd-doped $\mathrm{KF} / \mathrm{Al}_{2} \mathrm{O}_{3}$ catalyzed Suzuki coupling reactions. 
The use of palladium on carbon $(\mathrm{Pd} / \mathrm{C})$ is considered as an attractive supporting material in microwave-assisted organic synthesis, as carbon-support itself strongly absorbs most of the microwave energy [62]. Arvely and Leadbeater have studied cross-coupling reaction of aryl chlorides with phenylboronic acid in water as a solvent, using $\mathrm{Pd} / \mathrm{C}$ and under simultaneous microwave heating/cooling system. The microwave has been noticed to prolong the lifetime of the aryl chloride substrates (bearing electron-neutral or electron-donating substituents) and to yield the desired biaryl accompanied with unreacted aryl chlorides [63].

Ley and coworkers have described the application of palladium encapsulated catalyst (PdEnCat ${ }^{\mathrm{TM}}$ ) in Suzuki cross-coupling reactions in both conventional reflux and microwaves irradiation conditions. The EnCat has displayed significant catalytic performance and offered a facile workup procedure. The heterogeneous palladium catalyst is simply recovered by filtration, through a fritted sulfonic acid functionalized silica cartridge, and reused several times with less than $1 \%$ of palladium leaching from the content of the encapsulated catalyst, detected by inductively coupled plasma. With variety of boronic acids and aryl halides, the cross-coupling reactions were demonstrated in high yields using EnCat and tetrabutylammonium acetate $\left(n\right.$-Bu $\left.\mathrm{Bu}_{4} \mathrm{NOAc}\right)$ in acetonitrile or ethanol for $15 \mathrm{~min}$ at $140{ }^{\circ} \mathrm{C}$ under microwave condition (Scheme 25). The methodology has been used for the preparation of a library of biaryl derivatives through cross-coupling reaction between aryl bromides and boronic acids, whereas a single example with aryl chloride was successfully carried out under extended reaction time [64].
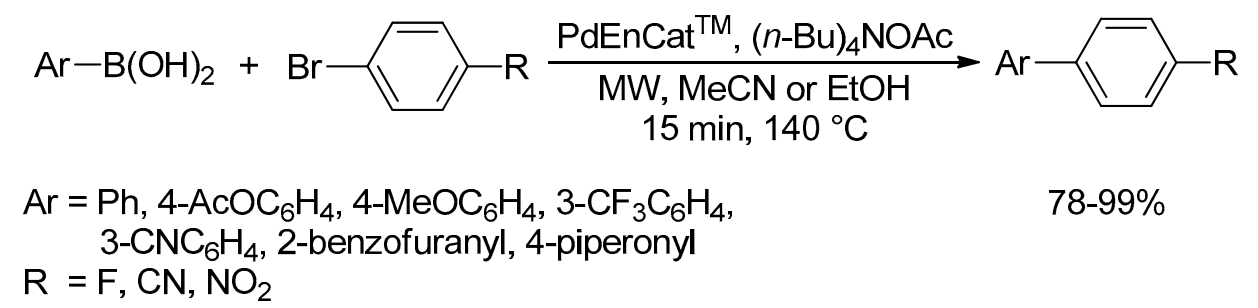

$78-99 \%$

Scheme 25. PdEnCat ${ }^{\mathrm{TM}}$ assisted Suzuki cross-coupling reactions of boronic acids and aryl halides.

In many cases, the use of ionic liquids as an alternative to conventional polar solvents is advantageous in term of shorter reaction time, complete conversion of staring materials, facile product separation, and high yields [65]. A number of guanidinium ionic liquids (GILs) have been reported to exhibit high catalytic activities and more stabilities of ligand-free metal catalyst under aqueous conditions. A catalyst system generated in situ from $\mathrm{Pd}(\mathrm{OAc})_{2}$, base $\left(\mathrm{K}_{2} \mathrm{CO}_{3}\right.$ or $\left.\mathrm{NBu}_{4} \mathrm{OH}\right)$ and GIL in aqueous ethanol was reported to synthesize biaryls in moderate to excellent yields via Suzuki cross-coupling of aryl halides with aryl phenylboronic acid under focused microwave irradiating for 10-40 $\mathrm{min}$ in an inert atmosphere (Scheme 26). During the reaction, well-dispersed $\operatorname{Pd}(0)$ species is generated in nano-scale and stabilized by guanidinium salt affording Pd micelle/GIL, which is responsible for enhancing the activity. Notably, GILs bearing long alkyl chains have demonstrated superior performance in the catalytic reaction than those with short alkyl substituents [66].

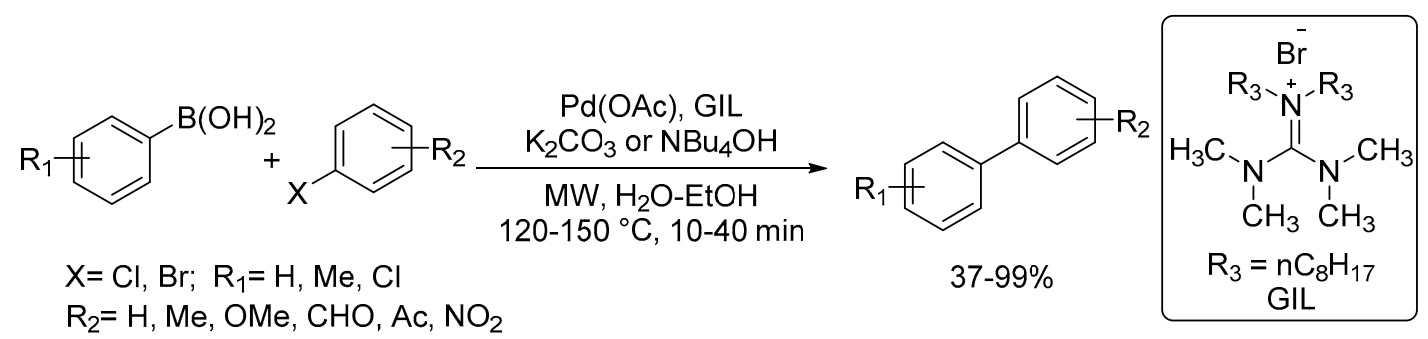

Scheme 26. Palladium-catalyzed cross-coupling reactions in guanidinium ionic liquids (GIL). 
Similar to the abovementioned protocol, glucose was used in isopropanol to stabilize the generated $\operatorname{Pd}(0)$ species instead of GIL for Suzuki-Miyaura cross-coupling reactions, but with limited examples of conversion of aryl iodides with phenyl boronic acid [67].

Recently, coordinated Pd(II) complex to 2,2'-dipyridylamine was immobilized on acidic resin polymer from gum resin, and employed in Suzuki-Miyaura coupling reactions. The Pd-loaded polymer was synthesized via nucleophilic substitution of 2-chloropyridine by 2-pyridylamine, affording 2,2'-dipyridylamine, which was reacted with acid chloride-functionalized polymer, and eventually coordinated with $\mathrm{Pd}(\mathrm{OAc})_{2}$ to provide the precatalyst. This heterogenized precatalyst has displayed high activity of coupling aryl halides and arylboronic acids under microwave irradiation. The presence of equimolar concentration of $\mathrm{Na}_{2} \mathrm{CO}_{3}$ is essential to afford moderate to excellent yields of the corresponding biaryls in aqueous ethanol at $120^{\circ} \mathrm{C}$ for $5 \mathrm{~min}$ (Scheme 27). The recyclability of the catalyst exhibited very good yields over three cycles (99\% to 93\%). However, the yield dropped to 53\% in the sixth cycle [68].

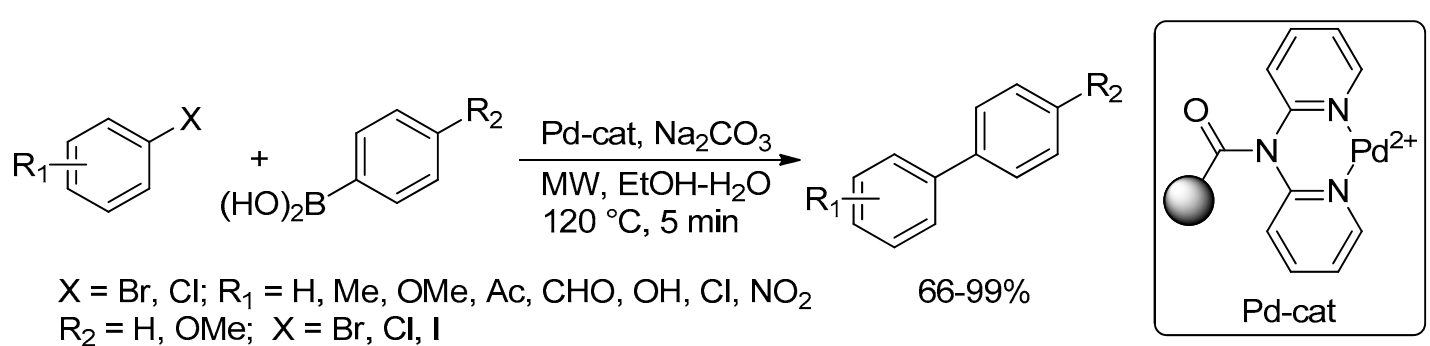

Scheme 27. Suzuki cross-coupling reactions through immobilize palladium-catalyst.

Natural halloysite nanotubes (HNT), a double-layered hollow cylinder of aluminosilicate mineral structure, have been recently employed to immobilize palladium particles. The external surface of the nanotubes was first embedded with 3-mercaptopropyl trimethoxysilane, followed by the reaction with vinylimidazolium ionic liquids and then treated with palladium particles [69]. The immobilized pd-precatalyst (HNT-Pd) was administered in in $0.1 \mathrm{~mol} \%$ or $1 \mathrm{~mol} \%$ for Suzuki reaction under microwave irradiation. The reaction of several types of aryl bromides and aryl iodides with phenylboronic acid yielded biphenyl compounds in high yield when the reactions were performed in the presence of $\mathrm{K}_{2} \mathrm{CO}_{3}$ as base in water-ethanol at $120^{\circ} \mathrm{C}$ for $10 \mathrm{~min}$. However, the reaction displayed a very less reactivity with aryl chlorides, its reactivity could be increased by either extending the reaction time or increasing the reaction temperature, Scheme 28 [70].

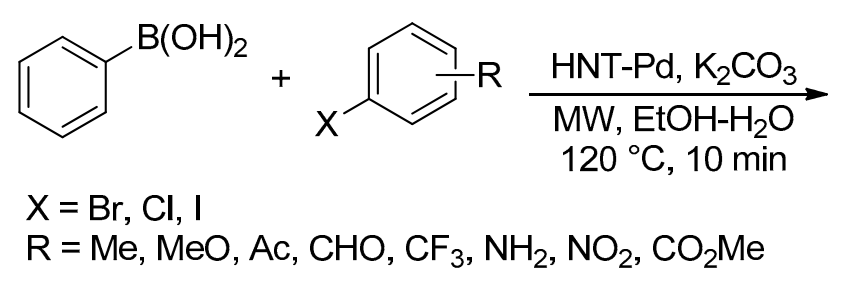<smiles>[R]c1ccc(-c2ccccc2)cc1</smiles>

conversion $14-99 \%$

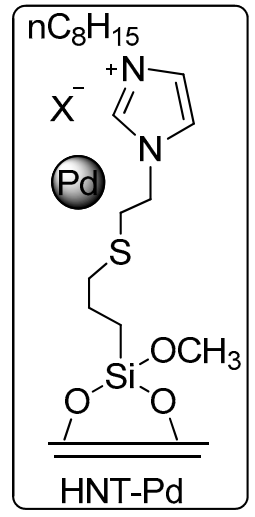

Scheme 28. Suzuki cross-coupling reactions through immobilize palladium-catalyst.

The heterogeneous catalyst system demonstrated a good recyclability between phenylboronic acid and 3-bromoanisole. The catalyst was recovered after each run by centrifugation, washed, dried, and reused again with freshly added solvent, starting materials, and base. A conversion of $90 \%$ in the 
cycle 1 was dropped to $88 \%$ in cycle 5 , revealing a marginal lose in the performance of immobilized palladium-catalyst. In a similar manner, palladium supported on halloysite-triazolium salt was synthesized and reported recently for Suzuki cross-coupling reactions [71].

The focus on employing biomaterial matrices to immobilize homogeneous palladium complexes received much attention in term of environmentally friendly catalysts. For instance, chitosan is extensively studied as a catalyst support material for having high affinity for metal ions. Baran et al. synthesized chitosan supported Pd catalyst and examined its catalytic activity in solvent-free microwave-assisted Suzuki reactions. Briefly, chitosan was condensed at reflux with mono-imine Schiff base ligand and then with monochloroacetic acid at $60^{\circ} \mathrm{C}$ for a week. The produced macromolecule was further reacted with $\mathrm{Na}_{2} \mathrm{PdCl}_{4}$ in aqueous media, giving rise to yellow-green biomaterial supported $\mathrm{Pd}$ catalyst. This precatalyst was used in $0.01 \mathrm{~mol} \%$ along with potassium carbonate at $50{ }^{\circ} \mathrm{C}$ for 4 min in cross-coupling reactions between different aryl halides with phenylboronic acids. Depending on the substituents and type of halides used, biaryls were considerably formed in different yields and as usual, aryl chloride displayed a poor conversion with phenylboronic acid (Scheme 29) [72]. Similarly, chitosan-Ulva (green alga) [73], sporopollenin microcapsule [74], and chitosan/cellulose [75] composites were employed recently as a palladium catalyst support in Suzuki coupling reactions under microwave irradiation conditions.
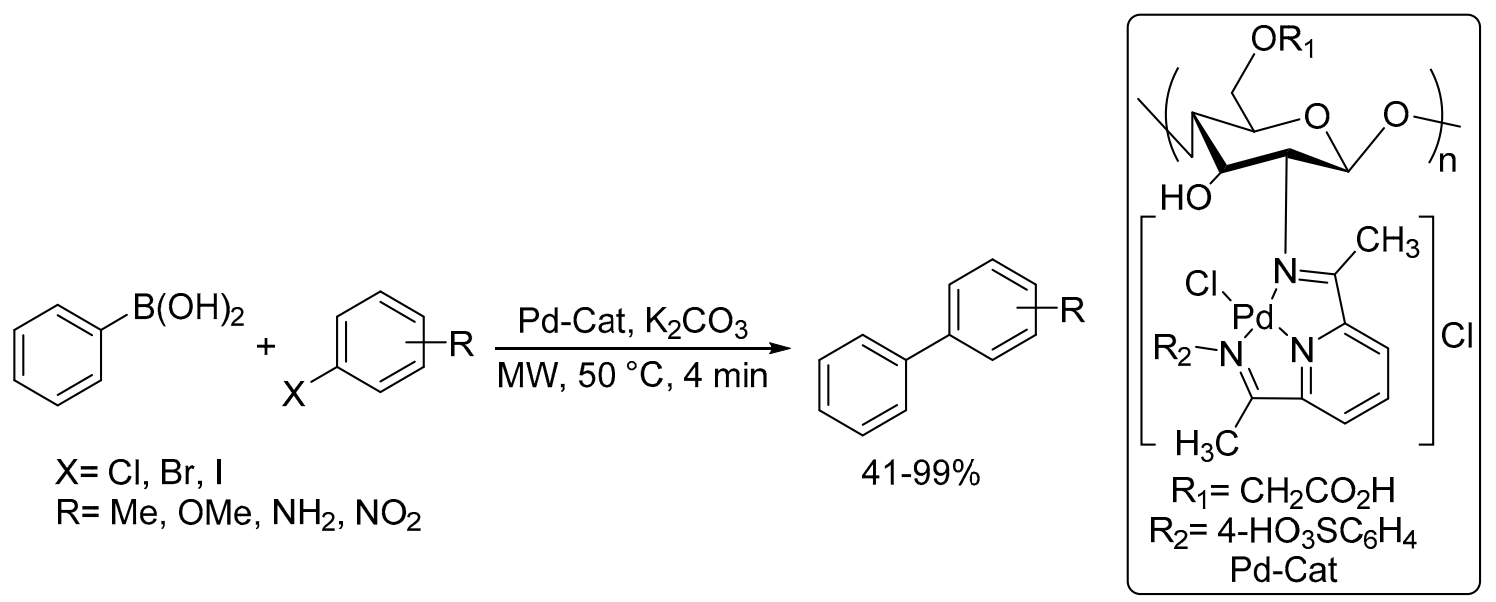

Scheme 29. Suzuki coupling reactions via chitosan-based palladium catalyst.

A variety of furocoumarin-biaryl derivatives was synthesized under conventional heating and microwave irradiation methods using water as solvent via Suzuki coupling reaction for evaluation of antimicrobial activity. As low conversion of starting materials was observed, the optimized reaction conditions include $10 \mathrm{~mol} \%$ of $\mathrm{Pd}\left(\mathrm{PPh}_{3}\right)_{4}$ with $\mathrm{Na}_{2} \mathrm{CO}_{3}$ as a base in aqueous phase under microwave heating. Scheme 30 illustrates the coupling reactions of bromo-furocoumarin derivatives with different arylboronic acids, affording the target products in high yields. Interestingly, part of the synthesized compounds demonstrated moderate to high antibacterial and antifungal activities compared to standard drugs Gatifloxacin and Clotrimazole, respectively [76]. 
<smiles>Cc1cc(=O)oc2c1ccc1oc(C(=O)c3ccc(Br)cc3)c(C)c12</smiles>

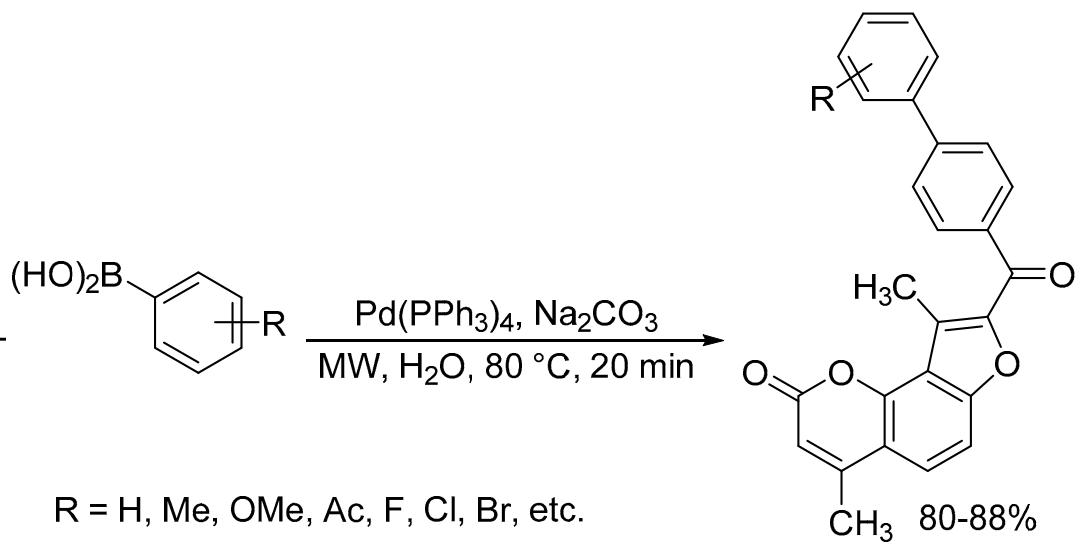

Scheme 30. Synthesis of furocoumarin-biaryl derivatives via cross-coupling reactions.

Palladacyclic complexes [77] have been described lately in a number of cross-coupling reactions. The Suzuki-Miyaura reaction of chloro uracil analogue with potassium aryltrifluoroborates $\left(\mathrm{ArBF}_{3} \mathrm{~K}\right)$, was recently reported to be mediated in water. Good to excellent yields of arylated uracil derivatives were obtained under optimized reaction conditions when $5 \mathrm{~mol} \%$ of Xphos-Pd-G2 (second generation XPhos precatalyst) was employed with three equiv. of cesium carbonate at $100{ }^{\circ} \mathrm{C}$ for an hour under microwave irradiation (Scheme 31). The $\mathrm{ArBF}_{3} \mathrm{~K}$ substrates have demonstrated excellent conversion with electron rich uracil analogue to products rather than other boron sources, such as $\operatorname{ArB}(\mathrm{OH})_{2}$ and $\operatorname{ArB}(\mathrm{OR})_{2}$. This is probably due to the presence of the boronic acid function, which might promote side reactions such as protodeboronation, oxidative homocoupling, and/or oxidative insertion. Thus, excess use of boronic acid is needed to direct the reaction toward completion [78]. Likewise, a water-soluble Pd-imidate complex has been utilized for the Suzuki-Miyaura cross-coupling of four different nucleosides with (hetero)arylboronic acids under microwave-assisted protocol [79]. Sodium tetraphenylborate was efficiently employed instead of $\operatorname{ArB}(\mathrm{OH})_{2}, \operatorname{ArB}(\mathrm{OR})_{2}$, or $\mathrm{ArBF}_{3} \mathrm{~K}$ in the cross-coupling reaction with four-fold of aryl bromides in the presence of different palladium catalysts under microwave heating, yielding a variety of biaryl derivatives [80,81].<smiles>Cn1c(=O)cc(Cl)[nH]c1=O</smiles>

$\mathrm{Ar}=\mathrm{Ph}, 2-\mathrm{MeC}_{6} \mathrm{H}_{4}, 4-\mathrm{MeOC}_{6} \mathrm{H}_{4}, 4-\mathrm{CF}_{3} \mathrm{C}_{6} \mathrm{H}_{4}, 4-\mathrm{AcC}_{6} \mathrm{H}_{4}$, 4- $\mathrm{ClC}_{6} \mathrm{H}_{4}$, 2-naphthyl, 3-quinolinyl, 2-biphenylyl, etc.<smiles>Cn1c(=O)cc(Cl)[nH]c1=O</smiles>

$72-92 \%$

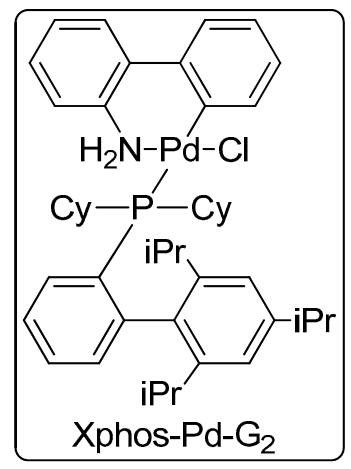

Scheme 31. Xphos-Pd-G2 catalyzed Suzuki-Miyaura cross-coupling reactions.

Lee et al. have examined the Suzuki coupling reactions of a broad selection of isomeric bromoimidazo[1,2-a]pyridines and substituted arylboronic acids. A range of arylated imidazo[1,2-a]pyridines were synthesized for biological studies under microwave irradiation conditions using $1 \mathrm{~mol} \%$ of $\mathrm{Pd}\left(\mathrm{PPh}_{3}\right)_{4}$ and an equimolar concentration of $\mathrm{Cs}_{2} \mathrm{CO}_{3}$ in $\mathrm{DMF}$ at $130{ }^{\circ} \mathrm{C}$ for $40 \mathrm{~min}$ (Scheme 32). In general, the presence of 2-substitutent on 3-bromoimidazo[1,2-a]pyridine did not display major steric effects with substituted arylboronic acids. Additionally, electron-donating or -withdrawing group on arylboronic acids did not affect the reaction outcomes, the resulting products were achieved in moderate to high yields [82]. 


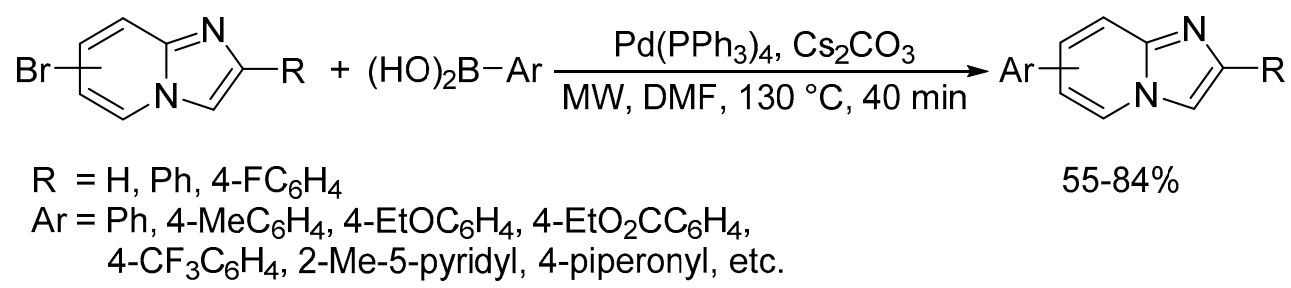

Scheme 32. Suzuki coupling reactions of bromoimidazo[1,2-a]pyridines and arylboronic acids.

A catalyst system designed and synthesized lately by dispersion of bimetallic $\mathrm{Pd}(\mathrm{II})-\mathrm{NiO}$ nanoparticles over microporous zeolite-NaY was described for the Suzuki-Miyaura cross-coupling reaction of aryl chlorides with arylboronic acid derivatives. In aqueous ethanol and in the presence of base $\left(\mathrm{K}_{2} \mathrm{CO}_{3}\right)$, a $30 \mathrm{mg}$ of loaded catalyst $(\mathrm{Pd}=2.62 \mathrm{mg} / 100 \mathrm{mg}, \mathrm{ICP})$ was considered to be the most suitable amount to selectively produce the biaryls using multimode microwave reactor at $30{ }^{\circ} \mathrm{C}$ with $80 \%$ power $(680 \mathrm{~W}$ ) (Scheme 33 ). The outcome of microwave irradiation for this reaction was compared against conventional heating, revealing that the yields of the reactions was almost double under irradiation conditions for $20 \mathrm{~min}$ and the biaryl products obtained in high yields. The Pd-NiO species were predicted as "true catalyst" by cyclic voltammetry study. Whereas, $\mathrm{NiO}$ represents as an active surface for redox reaction to in situ generated $\operatorname{Pd}(0)$, which represents the active species for $\mathrm{C}-\mathrm{Cl}$ bond activation step [83]. Though the reaction displayed high conversions of aryl chlorides, the generality of the reaction was demonstrated with a number of substrates.

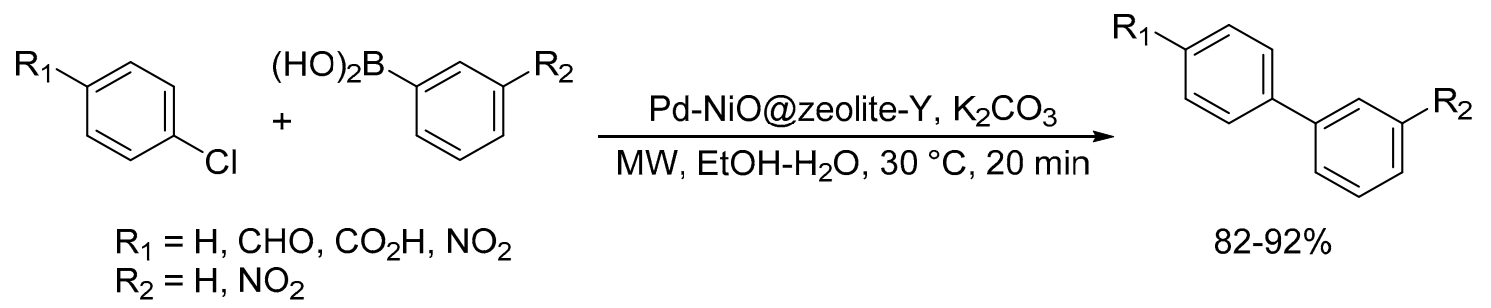

Scheme 33. Suzuki coupling reactions via $\mathrm{Pd}-\mathrm{NiO}$ nanocatalyst.

In a same manner, $\mathrm{Pd} / \mathrm{CuO}$ was described more recently for the cross-coupling of aryl boronic acids with aryl halides (I, Br, and $\mathrm{Cl}$ ) under irradiation conditions in aqueous ethanol, but with limited substrate scope [84]. Lately, water-soluble benzimidazole-Pd complex is described for Suzuki reaction of less-reactive aryl chlorides. The catalyst was synthesized via reaction of bis-benzimidazolyl-pyridine with 1,3-propanesulfonate, yielding the desired ligand which was subsequently coordinated with potassium tetrachloropalladate(II) $\left(\mathrm{K}_{2} \mathrm{PdCl}_{4}\right)$ to give a yellow solid of $\mathrm{Pd}(\mathrm{II})$ complex. Aqueous solution of this catalyst was used in $0.1 \mathrm{~mol} \%$ with $\mathrm{K}_{2} \mathrm{CO}_{3}$ in the coupling reaction between chlorobenzenes and arylboronic acids under microwave irradiation for $15 \mathrm{~min}$. Remarkably, the catalyst by itself showed moderate activity and increased by adding tetrabutylammonium bromide (TBAB) or 1-butyl-3-methylimidazolium hexafluoro-phosphate $\left(\mathrm{Bmim}-\mathrm{PF}_{6}\right)$ as an additive to replace the ionic potassium and stabilize the active $\operatorname{Pd}(0)$ species. Thus, electron rich aryl chlorides and sterically hindered substrates were smoothly transformed to biaryls in high yields, Scheme 34 [85]. Furthermore, a few number of palladium(II) complexes bearing amine-based ligands was reported as a homogeneous precatalyst for Suzuki-Miyaura cross-coupling reactions of boronic acids with mainly aryl bromides under microwave irradiation conditions $[86,87]$. 


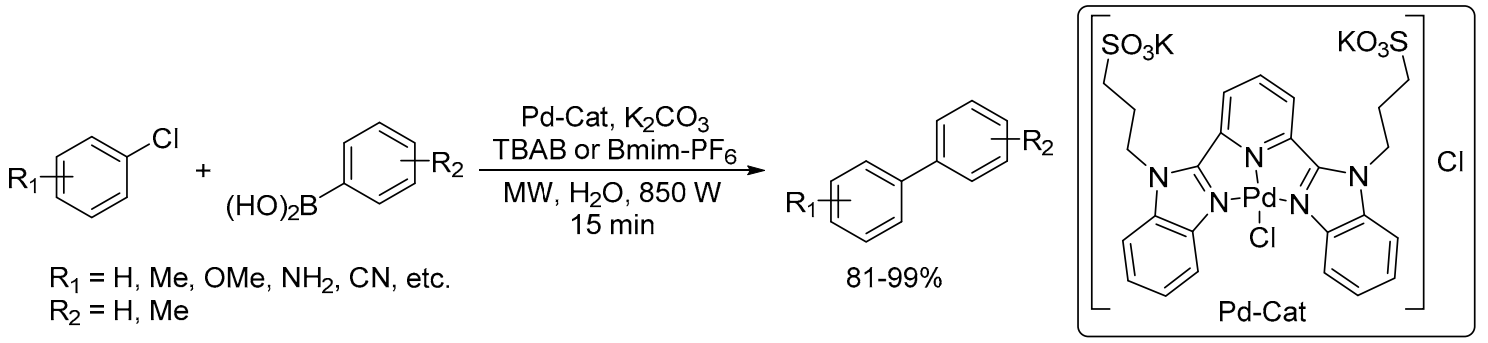

Scheme 34. Palladium-catalyzed Suzuki cross-coupling reactions.

Quite recently, an air and moisture stable starch-based Pd(II) catalyst was synthesized from functionalization of starch surface with 3-aminopropyl triethoxysilane. The formation of Schiff base was accomplished with 2-thiophenecarboxaldehyde in ethanol and the resulting ligand was eventually stirred with $\mathrm{Na}_{2} \mathrm{PdCl}_{4}$ in water. The $\mathrm{Pd}(\mathrm{II})$ catalyst was employed in Suzuki coupling reactions of aryl halides $(\mathrm{Cl}, \mathrm{Br}$, and $\mathrm{I})$ with phenyl boronic acid in the presence of potassium carbonate and under microwave irradiation conditions. Moderate to excellent yields of biphenyls were obtained in short reaction time at $50^{\circ} \mathrm{C}$ and high TONs and TOFs were achieved with very low catalyst loading. Moreover, the reusability of the catalyst was explored in 10 consecutive cycles, in which biphenyl yield decreased from 99 to $80 \%$, with very low leaching of palladium ion ( 1\%) per catalytic cycle (Scheme 35) [88]. It is worth mentioning that a good reaction yield was achieved starting from aryl chlorides, which often gives very low yield and in some cases resulted in no reactions, indicating the high robustness of the recently developed starch-based Pd-catalyst toward Suzuki cross-coupling reactions.

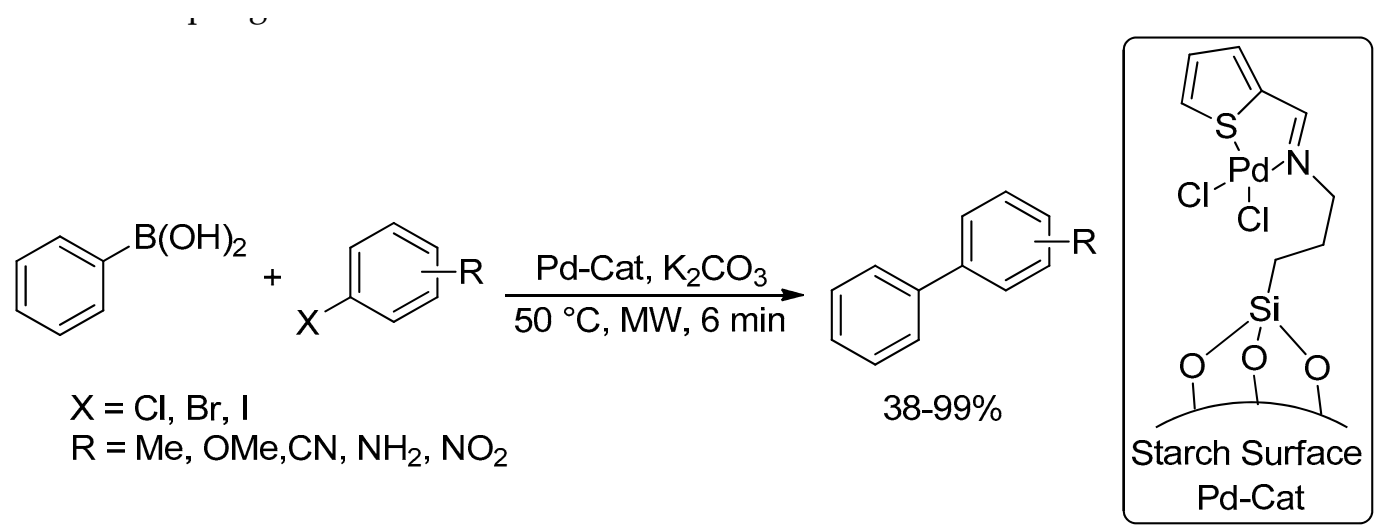

Scheme 35. Starch-based Palladium-catalyzed cross-coupling reactions.

\subsection{Stille Cross-Coupling Reaction}

Stille cross-coupling reaction was first described in 1978. It involves a reaction between organotin compounds (organostannanes) and a variety of arylhalides or arylpseudohalides via Palladium-catalyzed coupling reaction under almost base-free conditions. The reaction proceeds through the generation of active zerovalent palladium species in a conventional cross-coupling mechanism. Although the reaction is very stable to oxygen and moisture and tolerates numerous functional groups, it raises the environmental issue seriously for the employment of the toxic organostannanes [89]. Under microwave irradiation, nevertheless, the reaction has been widely employed in polymerizations [90] and few protocols have been developed and published during the last two decades. Microwave-accelerated one-pot hydrostannylation/Stille coupling reaction was reported for the conversion of 1-alkynes to 1,3-dienes or styrenes. To achieve efficient couplings, a mixture of $1 \mathrm{~mol} \%$ of $\mathrm{Pd}\left(\mathrm{PPh}_{3}\right)_{4}$, alkyne, $\mathrm{Bu}_{3} \mathrm{SnCl}$, aqueous $\mathrm{KF}$, polymethylhydrosiloxane (PMHS), and catalytic TBAF was irradiated using a domestic microwave. After $3 \mathrm{~min}$, the reaction vessel was cooled and charged with the electrophile and another $1 \mathrm{~mol} \%$ of Pd catalyst (once or twice within 
$5 \mathrm{~min}$, depending on the reaction progress). The benefit of portion addition of palladium precursor was anticipated to thermal decomposition of the palladium catalyst and the reduction of electrophile was often accompanied Stille products. Alkynes with trisubstituted at the propargylic position, phenyl acetylene, and methyl propiolate were highly biased toward the formation of the E-Stille products in high yields. However, less hindered alkynes typically afford isomeric mixtures in rather lower yields, likely because of postproduction isomerization, Scheme 36 [91].

$$
\begin{aligned}
\mathrm{R}_{1} & =+\mathrm{Bu}_{3} \mathrm{SnCl} \underset{\mathrm{N}}{\stackrel{1 . \mathrm{Pd}\left(\mathrm{PPh}_{3}\right)_{4}, \mathrm{KF}, \mathrm{PMHS}, \mathrm{TBAF}}{2 \cdot \mathrm{Br}-\mathrm{R}_{2}, \mathrm{MW}, \mathrm{THF}, 3 \mathrm{~min}}} \mathrm{R} \mathrm{R}_{1} / \mathrm{R}_{2} \\
\mathrm{R}_{1} & =\mathrm{t}-\mathrm{Bu}, \mathrm{C}(\mathrm{Me})_{2} \mathrm{OH}, \mathrm{CH}(\mathrm{OH}) \mathrm{Pr},\left(\mathrm{CH}_{2}\right)_{4} \mathrm{OH} \text {, etc } \\
\mathrm{R}_{2} & =\mathrm{Ph}, \mathrm{CH}_{2} \mathrm{Ph},(\mathrm{CH})_{2} \mathrm{Ph} \text {, etc }
\end{aligned}
$$

Scheme 36. Palladium-catalyzed one-pot hydrostannylation/Stille coupling reactions.

Likewise, $\mathrm{Pd}\left(\mathrm{PPh}_{3}\right)_{4}$ was reported as a rapid synthesis of biaryls in one-pot stannylation/Stille reaction of two aryl and/or heteroaryl bromides or iodide. Moderate to excellent yields were achieved in the presence of various functional groups such as: $\mathrm{F}, \mathrm{Ac}, \mathrm{CHO}, \mathrm{CF}_{3}, \mathrm{CN}, \mathrm{CO}_{2} \mathrm{Et}, \mathrm{CO}_{2} \mathrm{H}, \mathrm{OH}, \mathrm{OMe}$, and $\mathrm{NO}_{2}$ under microwave heating in water at $100{ }^{\circ} \mathrm{C}$ (Scheme 37). Although the one-pot approach comprises the elimination of the isolation/purification steps of the aryl stannanes, it should bypass the production of undesirable homocoupling resulting from stannylation reaction [92].

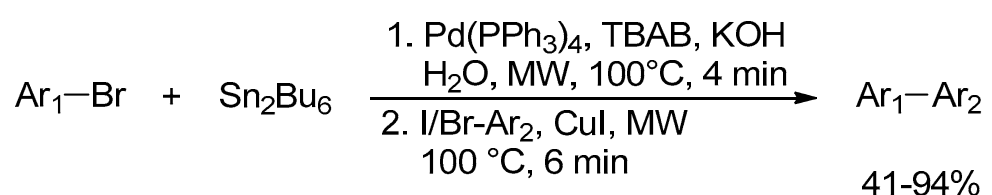

$$
\begin{aligned}
& \mathrm{Ar}_{1}=3-\mathrm{MeOC}_{6} \mathrm{H}_{4}, 2-\mathrm{MeC}_{6} \mathrm{H}_{4} \text {, 2-thienyl, etc } \\
& \mathrm{Ar}_{2}=4-\mathrm{NO}_{2} \mathrm{C}_{6} \mathrm{H}_{4}, 3-\mathrm{HOC}_{6} \mathrm{H}_{4} \text {, 3-thienyl, 2-pyridyl, etc }
\end{aligned}
$$

Scheme 37. Palladium-catalyzed one-pot hydrostannylation/Stille coupling reactions.

Van der Eycken and coworkers have described that Stille coupling reactions of few substrates were efficiently proceeded under microwave irradiation in moderate yields using $\mathrm{Pd}\left(\mathrm{PPh}_{3}\right)_{4}$, rather than under conventional heating condition. No improvement was observed when the abovementioned catalyst is replaced with more active ones like $\mathrm{Pd}(\mathrm{dppf}) \mathrm{Cl}_{2}$ or $\mathrm{Pd}_{2}(\mathrm{dba})_{3}$ and even in the presence of bulky phosphine ligands [93].

Stille cross-coupling reaction of 3,5-dibromo-1-methyl-1H-1,2,4-triazole with a selection of organotin derivatives was revealed for building polyheteroaryl systems bearing a 1,2,4-triazole unit. Cebrián et al. found that $\mathrm{PdCl}_{2}\left(\mathrm{PPh}_{3}\right)_{2} / \mathrm{LiCl}$ or $\mathrm{PdCl}_{2}\left(\mathrm{PPh}_{3}\right)_{2} / \mathrm{CuI}$ catalyzed the coupling partners under microwave at $110^{\circ} \mathrm{C}$ in solvent-free conditions for $15 \mathrm{~min}$ to produce the 5-monosubstituted 1,2,4-triazoles as the main or exclusive product in good yields. This suggest that the 5-position of 1,2,4-triazoles has the higher reactivity. However, when the reactive 2-thienyltin precursor had been used, a 3-substituted product was accomplished in small amount. $\mathrm{LiCl}$ was observed to be the additive of choice for five-membered heterocycles and aryl stannanes, while for six-membered heterocycles, stannanes favor the presence of $\mathrm{CuI}$ in order to give higher yields of the products and to accelerate the coupling reactions (Scheme 38). 


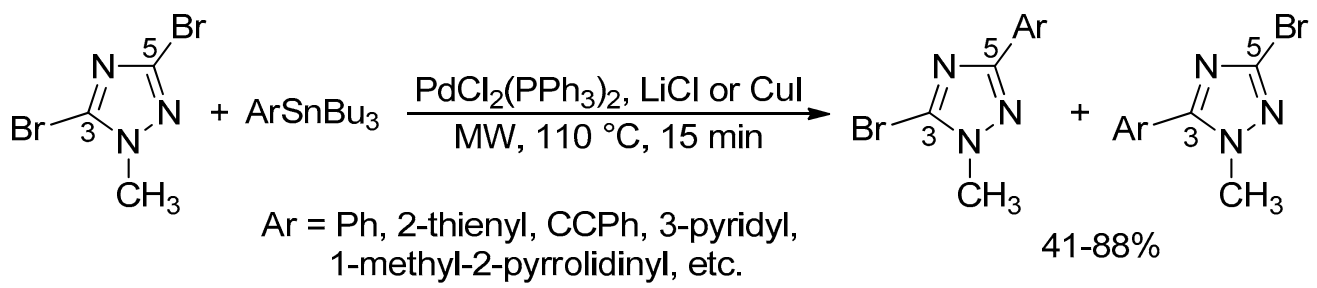

Scheme 38. Synthesis of polyheteroaryl systems via Stille coupling reactions.

The monosubstituted products were subjected to another coupling reaction, furnishing symmetric or asymmetric disubstituted 1,2,4-triazole derivatives. On the other hand, 1-phenyl-4-(tributylstannyl)-1H-1,2,3-triazole was reacted with different aryl or heteroaryl halides under microwave irradiation at $150^{\circ} \mathrm{C}$ for $15 \mathrm{~min}$, affording the 1,2,3-triazole derivatives in moderate to high yields (Scheme 39) [94].

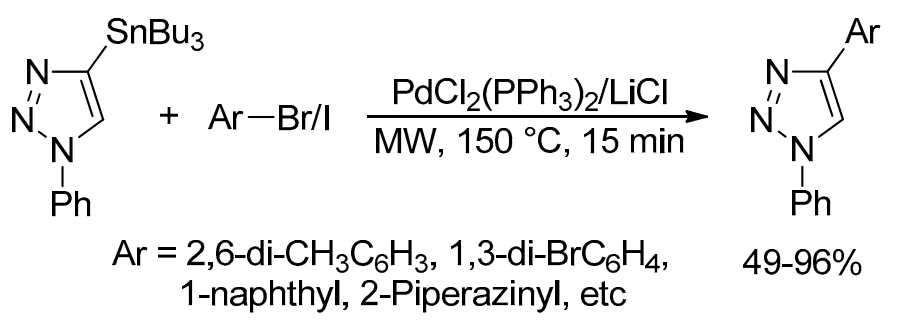

Scheme 39. $\mathrm{PdCl}_{2}\left(\mathrm{PPh}_{3}\right)_{2} / \mathrm{LiCl}$ mediated Stille coupling reactions.

Susanto et al. developed a light fluorous, thermally stable oxime-based palladacycle precatalyst for Stille reaction. The scope of the reaction was established with a variety of organostannanes and aryl halides in the presence of palladacycle $(0.005 \mathrm{~mol} \% \mathrm{Pd})$ and TBAB in water and under microwave irradiation for short reaction time at $100{ }^{\circ} \mathrm{C}$ for $5 \mathrm{~min}$ (Scheme 40). The recyclability of the catalyst was examined for the coupling reaction of tributyl(phenyl)stannane with iodobenzene under optimized conditions, stating that the yields over five runs were quantitative, as palladium leaching was very low. Remarkably, this palladacycle complex was demonstrated under microwave irradiation as a very efficient and versatile precatalyst for a wide range of cross-coupling reactions, including: Suzuki-Miyaura, Sonogashira, Heck, Glaser-type, and Kumada in either aqueous or organic medium [95].

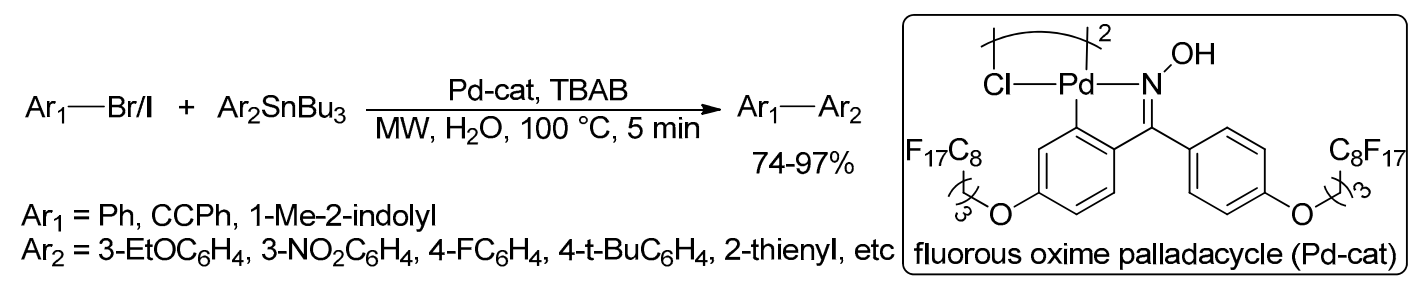

Scheme 40. Paladacycle-catalyzed Stille coupling reactions.

Similarly, an air and moisture stable palladacycle catalyst, $\left[\mathrm{Pd}\left\{\mathrm{C}_{6} \mathrm{H}_{4}\left(\mathrm{CH}_{2} \mathrm{~N}\left(\mathrm{CH}_{2} \mathrm{Ph}\right)_{2}\right)\right\}(\mu-\mathrm{Br})\right]_{2}$, was explored in the cross-coupling reaction of several aryl halides with phenyltributyltin derivatives under microwave irradiation in DMF at $100^{\circ} \mathrm{C}$, generating biaryls in high yield in 2-20 min [96].

Palladium nanoparticles generated in situ from $\mathrm{PdCl}_{2}-\mathrm{PEG} 400$ in the presence of DMAP was revealed recently for the production of a variety of functionalized biaryls. The cross-coupling reaction of one equiv. of tetraphenylstannane with 4 equiv. of aryl halides was conducted under microwave heating to afford the corresponding biaryls in high yields. In general, electron-withdrawing substituents on the aryl halides furnished higher yields than aryl halides with electron-donating substituents; biphenyl was 
produced in few examples as the only byproduct from homocoupling of tetraphenyltin (Scheme 41). The reusability of the catalyst was verified in the coupling of $\mathrm{SnPh}_{4}$ with 1-bromo-4-chlorobenzene. After extraction of organic material by diethyl ether, the remaining PEG400 and Pd nanoparticles were subjected to the next run. A yield of $94 \%$ was dropped to $81 \%$ from the fourth reuse of the catalyst even when the reaction time was prolonged to $40 \mathrm{~min}$. Though this protocol is considered as an atom-efficient approach, the commercial availability of a variety of tin-precursors (tetraorganotin compounds) is highly limited [97].

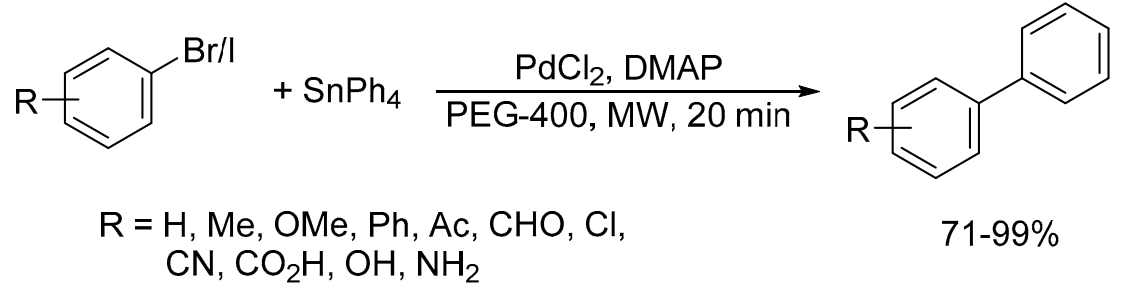

Scheme 41. In situ generated Pd nanoparticles mediated Stille coupling reactions.

\subsection{Negishi Cross-Coupling Reaction}

Negishi cross-coupling reaction was developed in 1977. It is frequently employed in industrial application processes for coupling organic halides or triflates with organozinc compounds using palladium(0) or palladium(II) species. Öhberg and Westman have reported the first Negishi coupling of 4-bromobenzaldehyde with 2-cyanophenylzinc-bromide under microwave condition. The biaryl was formed in $90 \%$ yield after $1 \mathrm{~min}$ at $160{ }^{\circ} \mathrm{C}$, Scheme 42 [98].

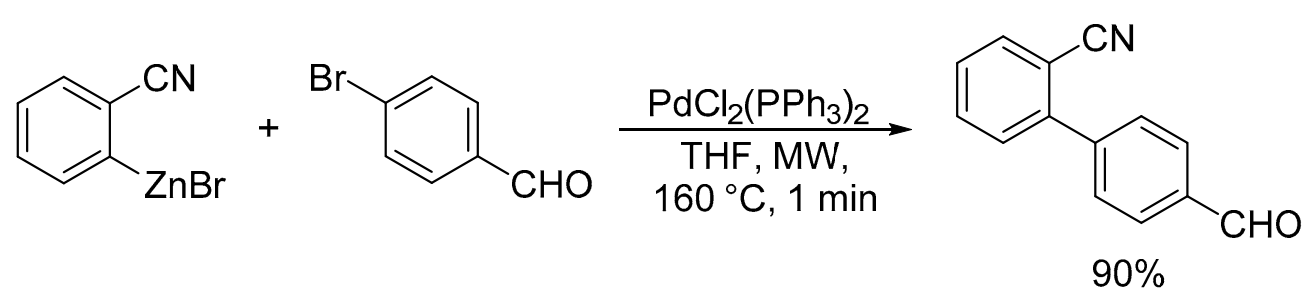

Scheme 42. Pd-catalyzed Negishi cross-coupling reaction.

However, the cross-coupling reaction of 2,4-dichloropyrimidine with organozinc reagents prepared from 2-fluoro-4-iodopyridine was investigated under microwave heating. The $\mathrm{Pd}\left(\mathrm{PPh}_{3}\right)_{4}$ allowed efficient access to mono-coupled compound in 90\% yield, in addition to $d i$-coupled compound (4\%) and traces of homo coupling product (Scheme 43) [99].

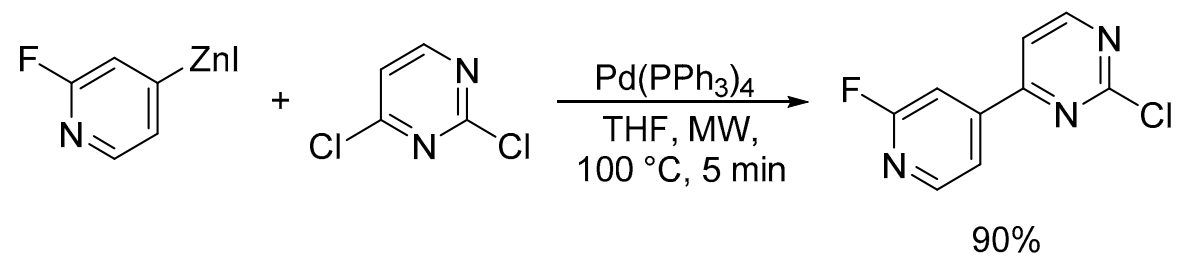

Scheme 43. Pd-catalyzed Negishi cross-coupling reaction.

Microwave-assisted Negishi coupling was developed using the $\mathrm{Pd}_{2}(\mathrm{dba})_{3} / t-\mathrm{Bu}_{3} \mathrm{P} \cdot \mathrm{HBF}_{4}$ system. The optimized reaction conditions were conducted using aryl zinc chlorides with electron-deficient and electron-rich aryl chlorides as coupling partners at $175^{\circ} \mathrm{C}$ for $10 \mathrm{~min}$, giving the corresponding products in good to high yields. Notably, the 4-nitrophenyl chloride was cross-coupled successfully with $n$-butyl zinc chloride within $30 \mathrm{~min}$ in $84 \%$ (Scheme 44) [100]. 


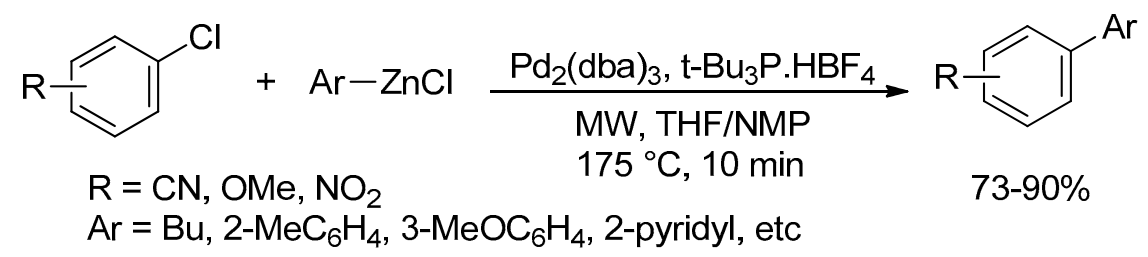

Scheme 44. Palladium-catalyzed Negishi coupling reactions.

An efficient approach to obtain arylzinc compounds for Negishi reaction is handling aryl chlorides or aryl bromides with magnesium turnings under microwave irradiation. A consequent transmetalation with $\mathrm{ZnCl}_{2}$-TMEDA generated the arylzinc species, which was directly introduced into a coupling reaction with aryl bromide derivatives using $\mathrm{Pd}\left(\mathrm{PPh}_{3}\right)_{2} \mathrm{Cl}_{2}$ as a precatalyst. The cross-coupling reaction was completed after irradiation at 80 or $120{ }^{\circ} \mathrm{C}$ in THF or THF-DMF mixture within a short time, depending on the substrates used. For instance, aryl chlorides did not react under the aforementioned conditions, while, the coupling reaction between 4-bromophenylzinc chloride and bromobenzaldehyde occurred at room temperature. The chemoselectivity of the reaction was obvious when 2-chloro-bromobenzene is employed, in which the cross-coupling took place selectively via bromide, affording the corresponding biaryl (Scheme 45) [101].

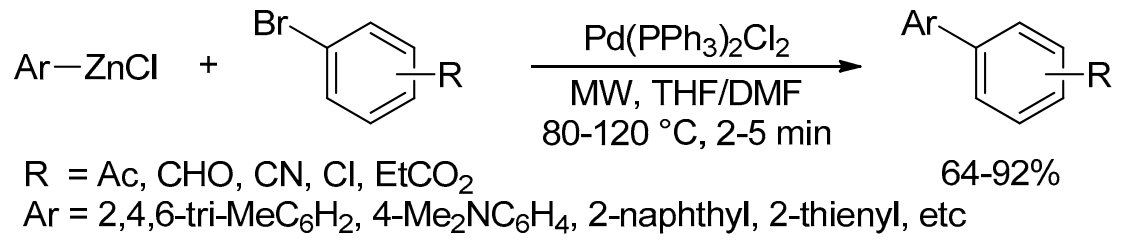

Scheme 45. Synthesis of biaryls via three-step reaction.

Espinet's group has disclosed a protocol for the synthesis of sterically hindered chiral binaphthalene derivatives. The enantioselective cross-coupling reactions were conducted between naphthylbromides and bis(naphthalen-1-yl)zinc compounds using $\mathrm{Pd}_{2} \mathrm{dba}_{3} \cdot \mathrm{CHCl}_{3}$ and a chiral ligand, $\left(\mathrm{R}, \mathrm{S}_{\mathrm{p}}\right)$-(2-diphenylphosphinoferrocenyl)ethyl-dimethylamine (L, Scheme 46). The coupling proceeded smoothly even with sterically demanding substrate $\left(R_{1}=R_{2}=M e\right)$ in THF at $100{ }^{\circ} \mathrm{C}$ within $45 \mathrm{~min}$ under an inert atmosphere. Alternatively, the authors have performed the same syntheses under Suzuki reaction conditions (using 1-naphthaleneboronic acids instead of bis(naphthalen-1-yl)zinc derivatives) achieving slightly better outcomes than the Negishi protocol [102].

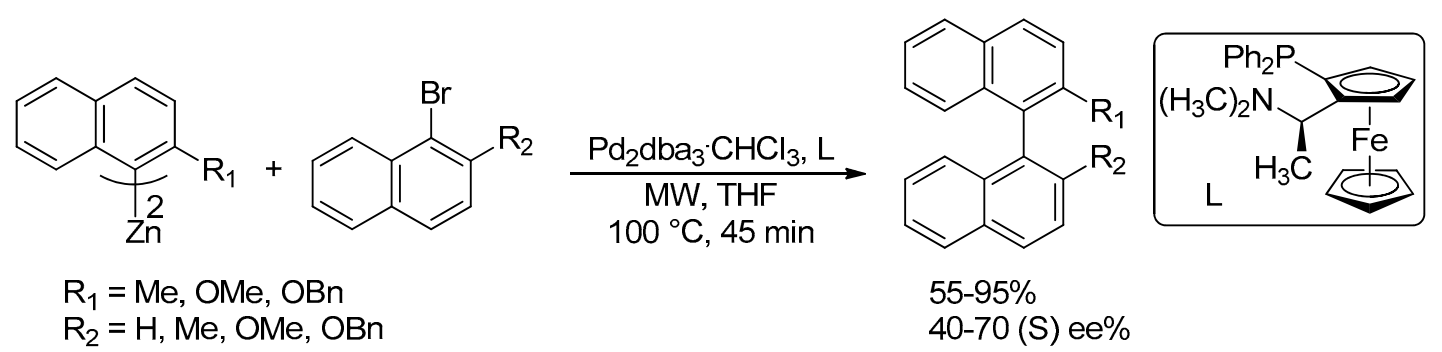

Scheme 46. Synthesis of chiral binaphthalene derivatives via Negishi cross-coupling reaction.

Recently, Motwani and Larhed have developed palladium-catalyzed carbonylative Negishi cross-couplings for aryl iodides and aryl bromides with benzylzinc bromide under controlled microwave irradiation. The carbonylative cross-coupling involves the introduction of $\mathrm{CO}$ between the coupling partners, using molybdenum hexacarbonyl as a solid in situ source of CO. As depicted in Scheme 47, the reaction conditions were optimized depending on the aryl halide used, to give a set of diarylated ethanones, a common pharmacophore, in moderate to high yields [103]. 


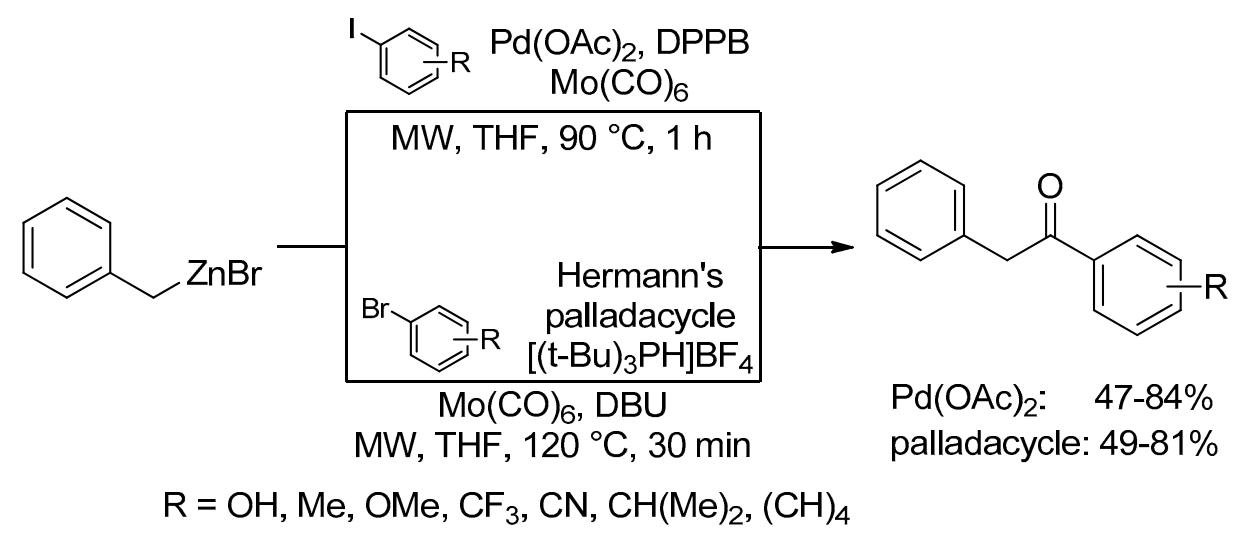

Scheme 47. Synthesis of biaryls via three-step reaction.

\subsection{Hiyama Cross-Coupling Reaction}

Hiyama cross-coupling reaction was first reported in 1988. In it, the $\mathrm{C}-\mathrm{C}$ bond formation takes place in the cross-coupled between organosilanes with aryl, vinyl, or alkyl halides or pseudohalides. The coupling reaction is analogous to the Suzuki reaction and an activating agent such as fluoride ion or a base is required to activate the organosilane reagent, via the formation of a pentavalent silicon center. This intermediate is unstable and permits facile breaking of a $\mathrm{C}-\mathrm{Si}$ bond in the transmetalation step [104].

The first microwave irradiation protocol was described within few minutes for Hiyama coupling reaction of aryl halides with aryl- or vinyl-siloxane derivatives. The reaction was activated using TBAF in THF, while the active catalyst species was generated in situ from $\left[\mathrm{Pd}(\right.$ allyl $) \mathrm{Cl}_{2}$ and $\mathrm{N}$-dicyclohexylphosphino- $\mathrm{N}$-methylpiperazine ( $\left.\mathrm{Cy}_{2} \mathrm{P}-\mathrm{N}-\mathrm{MePip}\right)$. Aryl bromide and activated aryl chlorides were proceeded smoothly, furnishing the desired products with high yields. However, deactivated aryl chlorides such as 4-chlorotoluene, with phenylsiloxane was transformed into a mixture of aromatic compounds along with a trace of the desired product, Scheme 48 [105].

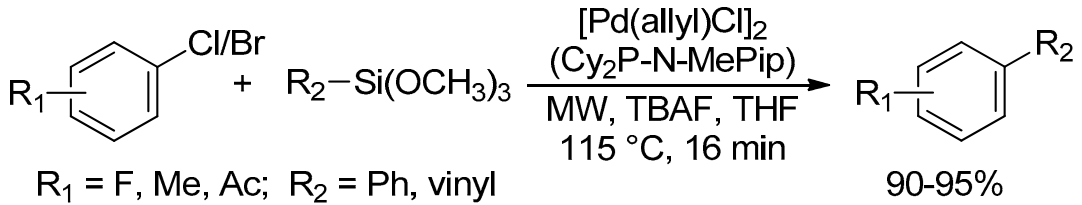

Scheme 48. Palladium-catalyzed Hiyama coupling reactions.

A precatalyst based on NHC-ligand prepared in situ from palladium acetate with 1-benzyl-3-(2-hydroxy-2-phenylethyl)-1H-imidazolium chloride was described as a fluorine-free Hiyama cross-coupling reactions of a range of aryl bromides with trimethoxy(phenyl)silane. The coupling was performed in the presence of $50 \%$ aqueous $\mathrm{NaOH}$, both activated and deactivated aryl bromides afforded the corresponding biaryls in good to high yields. Whereas, the use of TBAB in the coupling of heteroaryl bromides and chloroarens is necessary to improve the yield of the outcomes, since TBAB stabilizes the colloidal palladium nanoparticles. Other silicon-based reagents were conducted with aryl bromides under the optimized conditions to afford the biaryls, but in lower yields than the trimethoxy(phenyl)silane (Scheme 49) [106]. 


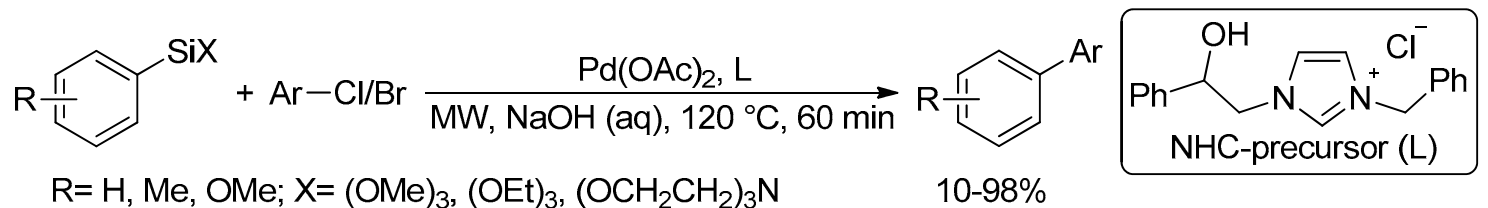

$\mathrm{Ar}=2-\mathrm{MeC}_{6} \mathrm{H}_{4}, 4-\mathrm{MeOC}_{6} \mathrm{H}_{4}, 4-\mathrm{AcC}_{6} \mathrm{H}_{4}$, 4-pyridyl, 3-thienyl

Scheme 49. Palladacycle-catalyzed Hiyama coupling reactions.

Hajipour and Rafiee have reported a thermally stable and oxygen insensitive monomeric palladacycle precatalyst for the synthesis of substituted biaryls. Under the optimized reaction conditions in DMF as the solvent and TBAF as the promoter, a selection of biaryls were produced in high yields when bromo- and iodoarens are employed. In contrast, good yields were achieved with chloroarens bearing electron-donating or electron-withdrawing substituents in short reaction time under microwave heating (Scheme 50) [107]. The same authors have revealed another protocol for Hiyama reaction of just about the same substrate scope, using palladium salt of 1-benzyl-4-aza-1-azoniabicyclo-[2.2.2]octane chloride and KF as an activator under microwave irradiation [108].

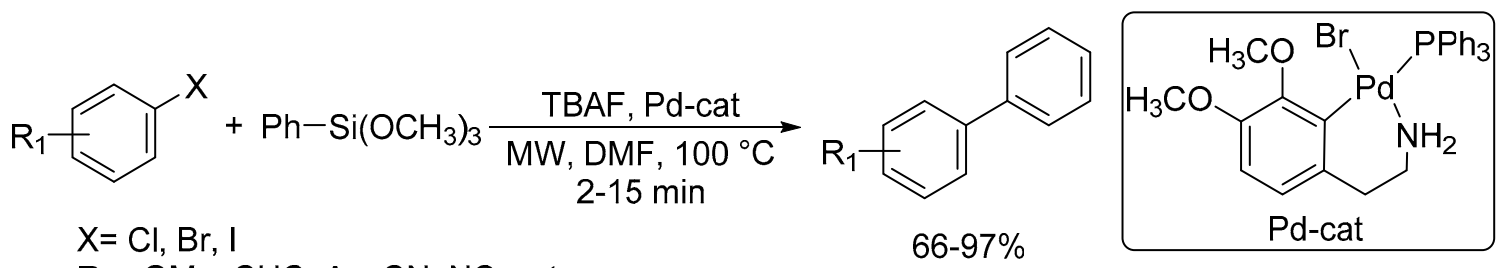

$\mathrm{R}_{1}=\mathrm{OMe}, \mathrm{CHO}, \mathrm{Ac}, \mathrm{CN}, \mathrm{NO}_{2}$, etc.

Scheme 50. Palladacycle-catalyzed Hiyama coupling reactions.

1-Methyl-2-aminoalkylimidazole derivative was reported as an efficient ligand for Hiyama reaction under solvent-free conditions in the presence of $\mathrm{Pd}(\mathrm{OAc})_{2}$. Aryl bromides with a range of electron-donating and electron-withdrawing substituents were cross-coupled with aryl(trimethoxy)silane, afforded the correspondent biaryls in good to high yields under irradiation conditions. The congested 2-bromotoluene yielded the coupling product in $85 \%$, while the 2-bromophenol coupled with $40 \%$ yield. This was rationalized for the poor reactivity, as the 2-bromophenol could deactivate the catalyst by coordination to the metal center. The reaction with heteroaryl halides and aryl chlorides was in general less effective (Scheme 51). Moreover, a variety of hydroxy- and amino-functionalized imidazoles were evaluated as efficient ligands for the palladium-catalyzed Hiyama reaction [109].

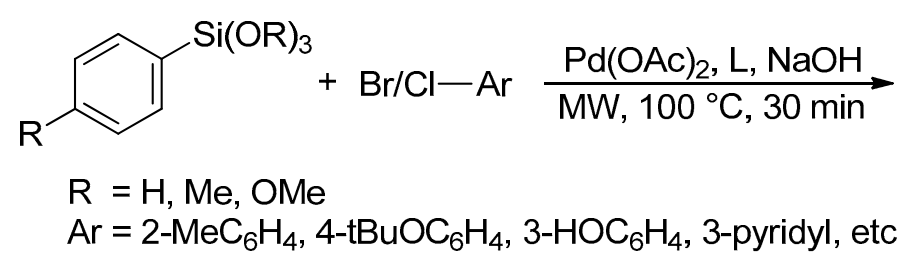<smiles>[R]c1ccc(Br)cc1</smiles><smiles></smiles>

Scheme 51. Palladacycle-catalyzed Hiyama coupling reactions.

On the other hand, the catalytic activity of the Pd-PVP nanoparticles toward the coupling reaction between phenyltrimethoxysilane and aryl halides was demonstrated with many examples of aryl bromides, and only two example of aryl chlorides. The reactions were performed in water using sodium hydroxide as the activator at $110^{\circ} \mathrm{C}$ for 6-9 min under microwave heating (Scheme 52). Despite the achievement of high yields using low catalyst-loading, the scope of the reaction was limited mainly to activated aryl halides. The reusability of the catalyst was evaluated in four consecutive runs displaying marginal decrease in the catalytic activity [110]. 


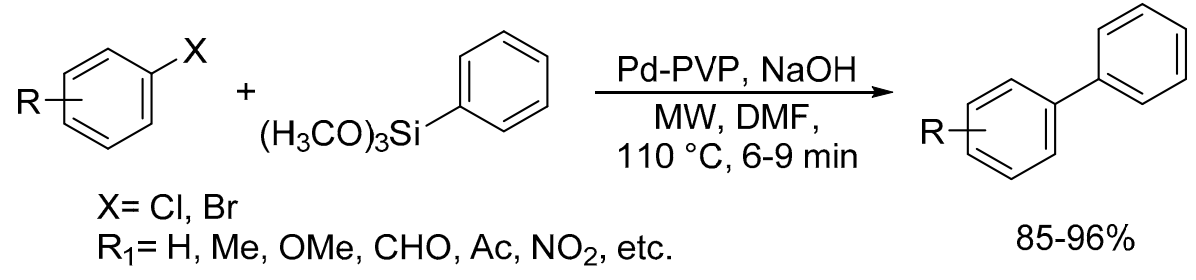

Scheme 52. Hiyama reactions of phenyltrimethoxysilane with aryl halides.

\subsection{Liebeskind-Srogl Cross-Coupling Reaction}

The Liebeskind-Srogl reaction was recently developed in 2000 [111]. It represents a powerful method developed lately for the construction of C-C bonds through the palladium-catalyzed cross-coupling of thio-organic compounds with various electrophilic reagents, such as boronic acids and organostannanes, in the presence of stoichiometric amount of copper salt [112,113].

For example, direct microwave-assisted $\mathrm{Pd}\left(\mathrm{PPh}_{3}\right)_{4}$-catalyzed desulfurative cross-coupling of thiourea compounds (3,4-dihydropyrimidine-2-thiones) and boronic acids were conducted in the presence of copper(I) thiophene-2-carboxylate (CuTC)-mediated conditions, leading to 2-aryl-1,4-dihydropyrimidines. Within few substrates the products were obtained in moderate to high yields, though this protocol represents the first direct coupling of thioureas under Liebeskind-Srogl conditions [114]. On the other hand, the cross-coupling reaction of substituted-pyrimidine-5-carboxylic acid thiol esters with aryl boronic acid gave the corresponding ketones in good yields in general. The reaction was proved to tolerate different substitutions on the pyrimidine scaffold and both electron-poor and electron-rich boronic acids as coupling partners in the presence of relatively inexpensive $\mathrm{Pd}(\mathrm{OAc})_{2}$ as a precatalyst, $\mathrm{PPh}_{3}$ as a ligand and CuTC as a co-catalyst under irradiation conditions for $1 \mathrm{~h}$ (Scheme 53) [115,116]. Similarly, arylation of functionalized 2-methylthiopyrimidine [117] and 4-phenylthiopyrimidine [118] derivatives with boronic acids were reported recently under microwave irradiation conditions.

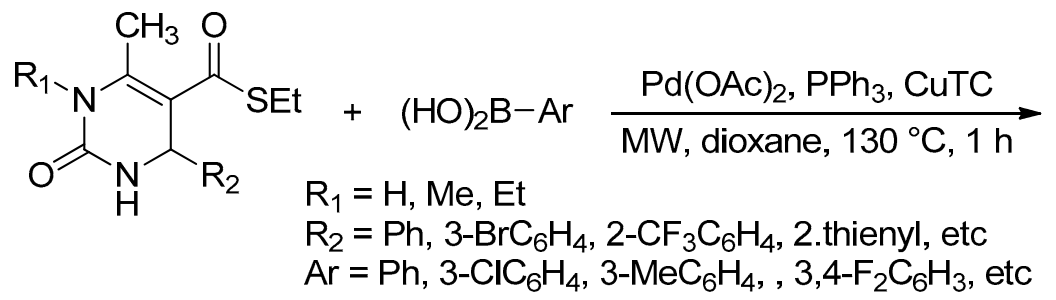<smiles>[R]C1NC(=O)N([R])C(C)=C1C(=O)[Al]</smiles>

$57-88 \%$

Scheme 53. Palladium-catalyzed Liebeskind-Srogl ketone synthesis.

Van der Eycken and coworkers have disclosed for the first time the Liebeskind-Sonogashira-type cross-coupling reaction between 5-chloro-3-(phenylsulfanyl) pyrazin-2(1H)-ones and terminal alkynes. The corresponding products, 5-chloro-3-alkynylpyrazinones, were obtained in moderate to high yields (Scheme 54). This transformation was performed satisfactorily when alkylthio substituent was present in the C3-position instead of a phenylthio substituent upon irradiation for $60 \mathrm{~min}$. The scope of the protocol was further extended to solid-phase-linked pyrazinones, oxazinones, pyrazines, and phenyl thioesters [119]. The same authors have reported thereafter an improved route toward pyrazine-containing nucleoside analogues under standard Liebiskind-Srogl conditions. When pyrazines bearing S-4-methoxybenzyl substituent reacted with boronic acids in the presence of $\mathrm{Pd}\left(\mathrm{PPh}_{3}\right)_{4}$ and CuTC in THF, the cross-coupled products were formed in good to high yields under irradiation conditions at $120^{\circ} \mathrm{C}$ for an hour [120]. 


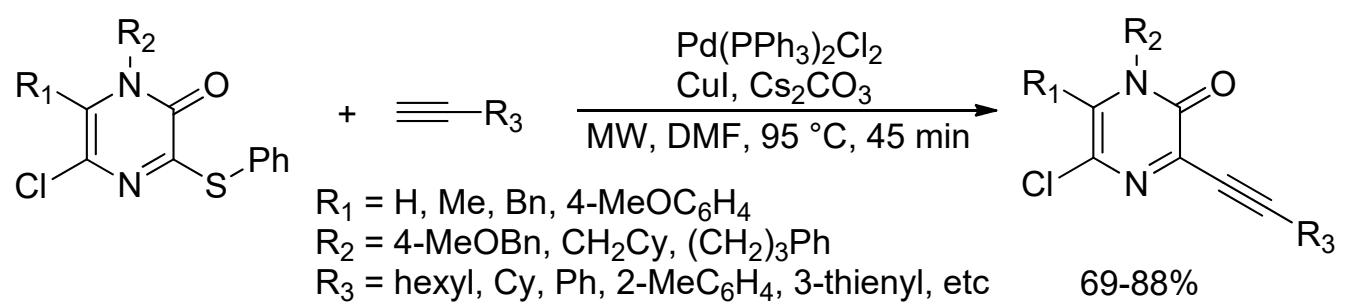

Scheme 54. Liebeskind-Sonogashira-type cross-coupling reactions.

On the other hand, a diversity of heteroaryl methylthioethers was cross-coupled with terminal alkynes. The full conversion of starting materials under microwave irradiation was not enough using $\mathrm{CuI}\left(0.2\right.$ equiv.), $\mathrm{Pd}(\mathrm{dppf}) \mathrm{Cl}_{2}$ ( 0.1 equiv.), and $\mathrm{Et}_{3} \mathrm{~N}$ ( 2 equiv.), unless another amounts of the catalysts and base were in need to be added freshly to the reaction mixture after half reaction time (overall 20 $\mathrm{mol} \% \mathrm{Pd}$ ). The limited conversion of starting materials was attributed to the catalyst, which could decompose under the applied reaction conditions (Scheme 55) [121].

$$
\begin{aligned}
& \mathrm{Ar}-\mathrm{SCH}_{3}+\equiv \mathrm{R} \frac{\mathrm{Pd}(\mathrm{dppf}) \mathrm{Cl}_{2}, \mathrm{Cul}^{\circ} \mathrm{Et}_{3} \mathrm{~N}}{\mathrm{MW}, \mathrm{THF}, 100{ }^{\circ} \mathrm{C}, 1-2 \mathrm{~h}} \quad \mathrm{Ar}=\mathrm{R} \\
& \mathrm{Ar}=\text { 2-pyridyl, 2-pyrazinyl, 2-furyl, 2-thiazolyl } \\
& \mathrm{R}=\mathrm{Cy} \text {, n-Bu, Ph, 4-MeOC } \mathrm{H}_{4}, 4-\mathrm{HC}_{6} \mathrm{H}_{4}, 4-\mathrm{CNC}_{6} \mathrm{H}_{4}
\end{aligned}
$$

Scheme 55. Sonogashira-type reaction of aryl methyl-thioethers with terminal alkynes.

Prieur et al. have described a selective strategy for the arylation of 4-chloro-2-(methylthio)pyrrolo[3,2- $d$ ]pyrimidine derivatives under Suzuki-Miyaura and Liebeskind-Srog conditions subsequently. The later was performed between 4-aryl-2-(methylthio)pyrrolo[3,2-d]pyrimidines and boronic acids using $\mathrm{Pd}\left(\mathrm{PPh}_{3}\right)_{4}$ and copper(I) 3-methylsalicylate (CuMeSal) in THF at $100{ }^{\circ} \mathrm{C}$ for $1 \mathrm{~h}$ (Scheme 56). The desulfurative reaction proceeded smoothly in the presence of either electron-donating, electron-withdrawing, or heterocyclic substituents on the arylboronic acids, leading to the products in high yields [122].<smiles>[R][R]#[R][R]</smiles>

Scheme 56. Palladium-catalyzed desulfurative cross-coupling reactions.

The Liebeskind-Srogl reaction was further employed as the key step to combine the two fragments together in a multi-step synthesis of cholesterol analogues [123], and in the synthesis of cannabinergic ligands, namely C1'-azacycloalkyl hexahydrocannabinols [124]. Moreover, the Soai-type aldehydes were obtained in a single-step synthesis from dehydrosulfurative coupling of terminal alkynes with 2-mercapto-1,3-pyrimidine-5-carbaldehyde under base-free conditions in low to high yields, Scheme $57[125,126]$. 


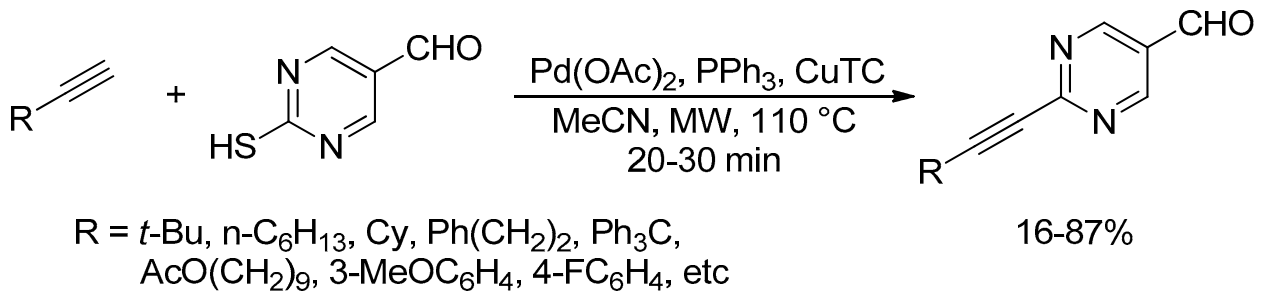

Scheme 57. Synthesis of Soai-type aldehydes from dehydrosulfurative reactions.

\subsection{Other Cross-Coupling Reaction}

Although there are a number of cross-coupling protocols developed during the past few decades, the fascination by the scientific community is far less comparing with the aforementioned approaches. The Kumada reaction is one of these protocols reported scarcely in the peer-reviewed literature, particularly under microwave conditions, because of the sensitivity of the organomagnesium halides (Grignard reagents) as coupling partners. Within single example, this type of cross-coupling was described as a proof of concept under microwave conditions [100]. Nevertheless, the synthesized oxime-based palladacycle precatalyst (see Scheme 40) was employed in very low catalyst loading $(0.05 \mathrm{~mol} \%)$ in coupling reaction between different combinations of alkyl halides and Grignard reagents, leading to high yields of the anticipated product (Scheme 58). The recyclability of the catalyst was carried out using phenylmagnesium bromide and bromobenzene under the optimized reaction conditions. A yield of $91 \%$ was dropped to $63 \%$ in the fourth run because of Pd leaching, observed as a black precipitated formed during the reaction [95].

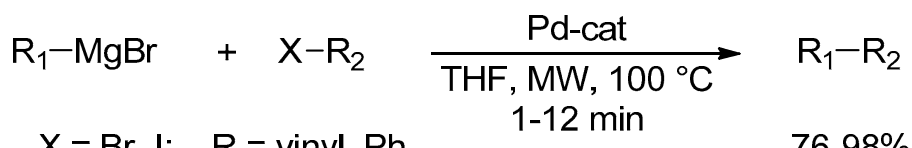

$$
\begin{aligned}
& \mathrm{X}=\mathrm{Br}, \mathrm{I} ; \quad \mathrm{R}=\text { vinyl, } \mathrm{Ph} \\
& \mathrm{R}_{2}=\text { n-hexyl, } \mathrm{Ph}, 4-\mathrm{MeOC}_{6} \mathrm{H}_{4}, 4-\mathrm{NO}_{2} \mathrm{C}_{6} \mathrm{H}_{4} \text {, } \\
& \text { 5-pyrimidinyl, 9-anthracenyl, etc }
\end{aligned}
$$

Scheme 58. Paladacycle-catalyzed Kumada coupling reactions.

Finze's group has reported on the Kumada-type cross-coupling reaction of mono- and $d i$-iodinated carba-closo-dodecaborate anions with various Grignard reagents. The coupling products were obtained under microwave conditions in high yields and shorter reaction times using $\mathrm{PdCl}_{2} \mathrm{P}\left(\mathrm{Ph}_{3}\right)_{2}$ in THF at about $60{ }^{\circ} \mathrm{C}$ (Scheme 59) [127].

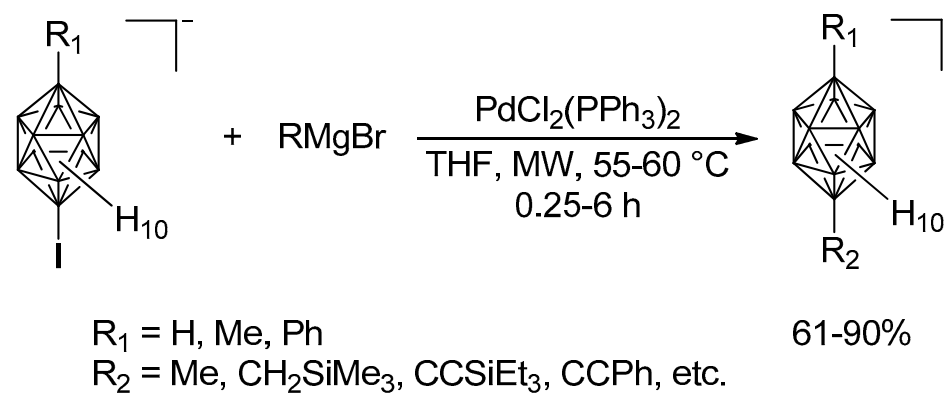

Scheme 59. Microwave-assisted Kumada-type cross-coupling reactions.

Recently, decarboxylative cross-coupling reactions were found to be an appealing source for the generation of $\mathrm{C}-\mathrm{C}$ bond. In this type of reaction, the relatively inexpensive carboxylic acid salt reacts with an organic halide or pseudohalides to form biaryls with the loss of $\mathrm{CO}_{2}$ [128]. Gooßen and coworkers have developed a palladium-catalyzed synthesis of biaryls derivatives from the decarboxylative cross-coupling of carboxylic acid salts with aryl bromides in the presence of CuI 
as a cocatalyst under microwave conditions. The reaction has proceeded smoothly with potassium 2-nitrobenzoate and numerous electron-rich and electron-poor aryl bromides in moderate to high yields in $5 \mathrm{~min}$. However, the 4-bromotoluene was converted to the corresponding products (31-87\%) when conducted with a range of arenecarboxylic acid salts (Scheme 60). Under similar conditions, few examples of aryl ketones were achieved from the coupling of $\alpha$-oxocarboxylates with aryl bromides [129]. The same group has also disclosed another protocol for the decarboxylative coupling of aryl tosylates with aromatic carboxylate salts. In this approach, biaryl derivatives were obtained in good yields using $\mathrm{Pd}(\mathrm{acac})_{2} / \mathrm{XPhos}$ as a catalyst and $\mathrm{CuO} / 1,10$-phenanthroline as a co-catalyst to facilitate the decarboxylative step under microwave irradiation for 2-5 $\min$ [130].

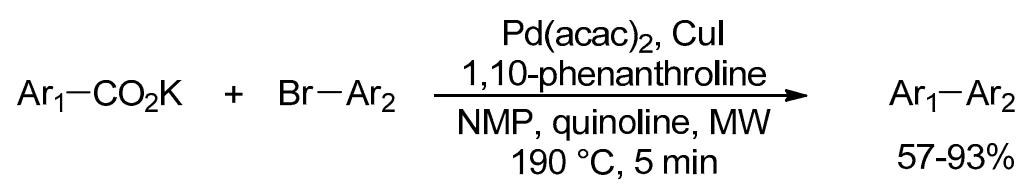

$\mathrm{Ar}_{1}=2-\mathrm{NO}_{2} \mathrm{C}_{6} \mathrm{H}_{4}, 2-\mathrm{AcC}_{6} \mathrm{H}_{4}, 2-\mathrm{NCC}_{6} \mathrm{H}_{4}$, 2-thinyl, 1-naphthyl, etc $\mathrm{Ar}_{2}=4-\mathrm{MeC}_{6} \mathrm{H}_{4}, 4-\mathrm{MeOC}_{6} \mathrm{H}_{4}, 4-\mathrm{ClC}_{6} \mathrm{H}_{4}$, 3-pyridyl, 2-naphthyl, etc

Scheme 60. Palladium-catalyzed decarboxylative cross-coupling reactions.

Behrends et al. has described the desulfinative cross-coupling of aryl sulfinates and nitriles using $\mathrm{Pd}\left(\mathrm{O}_{2} \mathrm{CCF}_{3}\right)_{2}$ and 6-methyl-2,2'-bipyridyl (MBP) as a catalytic system and trifluoroacetic acid (TFA) as additive in water-THF. The scope of the microwave protocol was investigated with diverse sulfinates and a range of nitriles bearing electron-rich and electron-deficient substituents, leading to the aryl ketones relatively in good to high yields in addition to the corresponding amides, resulting as a byproduct from the hydration of the organic nitriles (Scheme 61). Remarkably, few selected substrates were performed using a heating block, giving relatively lower yields [131].

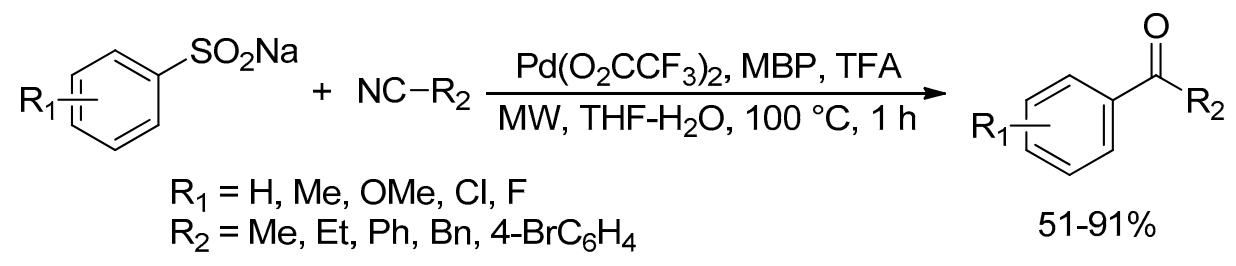

Scheme 61. Palladium-catalyzed desulfinative cross-coupling reactions.

Allylic substitution has been scarcely reported in the literature, although it is useful in the syntheses of valuable chemical structures. The coupling reaction of diacetate diene substrate with a number of nucleophiles, include carbon nucleophiles afforded for the most part the expected di-substituted dienyl derivatives in low yields under irradiation condition for $20 \mathrm{~min}$, using $\mathrm{Pd}(\mathrm{OAc})_{2} / \mathrm{PPh}_{3}$ as a catalyst precursor in aqueous ethanol (Scheme 62) [132].

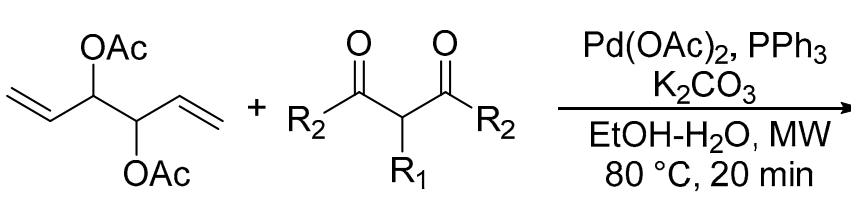

$\mathrm{R}_{1}=\mathrm{H}, \mathrm{CH}_{3} ; \mathrm{R}_{2}=\mathrm{Me}, \mathrm{EtO}$<smiles>[R]C(=O)C([R7])(C/C=C/C=C/CC([R7])(C([R2])=O)C([R])=O)C([R2])=O</smiles>

$36-38 \%$

Scheme 62. Pd-catalyzed allylic substitution reactions.

\section{Conclusions}

Palladium-catalyzed cross-coupling to generate C-C bond, such as Negishi, Heck, Kumada, Sonogashira, Stille, Suzuki, and Hiyama, under microwave condition has proved to be safe in 
handling and cost effectiveness. It is well-known that the use of microwave technology to heat reactions would shorten the reaction time, but, in some cases, it was crucial for obtaining the desired products and to improve the yield of the products. It is worth mentioning that before developing and investigating cross-coupling reaction, the use of aqua regia to clean stirring bars and glassware are highly recommended, since palladium contamination down to level $50 \mathrm{ppb}$ will be accountable for the generation of coupling product [133]. Moreover, the main advantage of solid support is the consecutive use of the materials (recycling of the catalyst). Finally, we hope that this review will inspire scientists for further exploration of the microwave irradiation in organic synthesis and to make this technology widely available soon.

Author Contributions: Both authors contributed equally to this work. All authors have read and agreed to the published version of the manuscript.

Funding: This work was supported by Arab-German Young Academy of Sciences and Humanities (AGYA) grants (TP_2018_29 \& TP_2019_04).

Acknowledgments: The publication of this article was funded by the Qatar National Library.

Conflicts of Interest: The authors declare no conflict of interest.

\section{References}

1. Pagliaro, M.; Pandarus, V.; Ciriminna, R.; Béland, F.; Carà, P.D. Heterogeneous versus Homogeneous Palladium Catalysts for Cross-Coupling Reactions. ChemCatChem 2012, 4, 432-445. [CrossRef]

2. Salih, K.S.M.; Thiel, W.R. Palladium-Catalyzed Coupling Reactions with Magnetically Separable Nanocatalysts. In Palladium-Catalyzed Coupling Reactions: Practical Aspects and Future Developments, 1st ed.; Molnár, Á., Ed.; Wiley-VCH Verlag GmbH \& Co. KGaA: Weinheim, Germany, 2013; pp. 57-78.

3. Roya, D.; Uozumia, Z. Recent Advances in Palladium-Catalyzed Cross-Coupling Reactions at ppm to ppb Molar Catalyst Loadings. Adv. Synth. Catal. 2018, 360, 602-625. [CrossRef]

4. De la Hoz, A.; Loupy, A. Microwaves in Organic Synthesis, 3rd ed.; Wiley-VCH Verlag GmbH \& Co. KGaA: Weinheim, Germany, 2013.

5. Gawande, M.B.; Shelke, S.N.; Zboril, R.; Varma, R.S. Microwave-Assisted Chemistry: Synthetic Applications for Rapid Assembly of Nanomaterials and Organics. Acc. Chem. Res. 2014, 47, 1338-1348. [CrossRef]

6. Larhed, M.; Moberg, C.; Hallberg, A. Microwave-Accelerated Homogeneous Catalysis in Organic Chemistry. Acc. Chem. Res. 2002, 35, 717-727. [CrossRef]

7. Kappe, C.O. Controlled Microwave Heating in Modern Organic Synthesis. Angew. Chem. Int. Ed. 2004, 43, 6250-6284. [CrossRef]

8. Barge, A.; Tagliapietra, S.; Tei, L.; Cintas, P.; Cravotto, G. Pd-catalyzed Reactions Promoted by Ultrasound and/or Microwave Irradiation. Curr. Org. Chem. 2008, 12, 1588-1612. [CrossRef]

9. Heck, R.F.; Nolley, J.P., Jr. Palladium-Catalyzed Vinylic Hydrogen Substitution Reactions with Aryl, Benzyl, and Styryl Halides. J. Org. Chem. 1972, 37, 2320-2322. [CrossRef]

10. Mizoroki, T.; Mori, K.; Ozaki, A. Arylation of Olefin with Aryl Iodide Catalyzed by Palladium. Bull. Chem. Soc. Jpn. 1971, 44, 581. [CrossRef]

11. Beletskaya, I.P.; Cheprakov, A.V. The Heck Reaction as a Sharpening Stone of Palladium Catalysis. Chem. Rev. 2000, 100, 3009-3066. [CrossRef] [PubMed]

12. Jagtap, S. Heck Reaction-State of the Art. Catalysts 2017, 7, 267. [CrossRef]

13. Cabri, W.; Candiani, I. Recent Developments and New Perspectives in the Heck Reaction. Acc. Chem. Res. 1995, 28, 2-7. [CrossRef]

14. Arvela, R.K.; Pasquini, S.; Larhed, M. Highly Regioselective Internal Heck Arylation of Hydroxyalkyl Vinyl Ethers by Aryl Halides in Water. J. Org. Chem. 2007, 72, 6390-6396. [CrossRef] [PubMed]

15. Olofsson, K.; Larhed, M.; Hallberg, A. Highly Regioselective Palladium-Catalyzed Internal Arylation of Allyltrimethylsilane with Aryl Triflates. J. Org. Chem. 1998, 63, 5076-5079. [CrossRef]

16. Datta, G.K.; von Schenck, H.; Hallberg, A.; Larhed, M. Selective Terminal Heck Arylation of Vinyl Ethers with Aryl Chlorides: A Combined Experimental-Computational Approach Including Synthesis of Betaxolol. J. Org. Chem. 2006, 71, 3896-3903. [CrossRef] [PubMed] 
17. Vallin, K.S.A.; Emilsson, P.; Larhed, M.; Hallberg, A. High-Speed Heck Reactions in Ionic Liquid with Controlled Microwave Heating. J. Org. Chem. 2002, 67, 6243-6246. [CrossRef] [PubMed]

18. Demel, J.; Park, S.-E.; Čejka, J. Štěpniěka, P. The use of palladium nanoparticles supported with MCM-41 and basic (Al)MCM-41 mesoporous sieves in microwave-assisted Heck reaction. Catal. Today 2008, 132, 63-67. [CrossRef]

19. Choudary, B.M.; Madhi, S.; Chowdari, N.S.; Kantam, M.L.; Sreedhar, B. Layered Double Hydroxide Supported Nanopalladium Catalyst for Heck-, Suzuki-, Sonogashira-, and Stille-Type Coupling Reactions of Chloroarenes. J. Am. Chem. Soc. 2002, 124, 14127-14136. [CrossRef]

20. Ratti, R. Ionic Liquids: Synthesis and Applications in Catalysis. Adv. Chem. 2014, 2014, 729842. [CrossRef]

21. Xie, X.; Lu, J.; Chen, B.; Han, J.; She, X.; Pan, X. Pd/C-catalyzed Heck reaction in ionic liquid accelerated by microwave heating. Tetrahedron Lett. 2004, 45, 809-811. [CrossRef]

22. Glasnov, T.N.; Stadlbauer, W.; Kappe, C.O. Microwave-Assisted Multistep Synthesis of Functionalized 4-Arylquinolin-2(1H)-ones Using Palladium-Catalyzed Cross-Coupling Chemistry. J. Org. Chem. 2005, 70, 3864-3870. [CrossRef]

23. Du, L.-H.; Wang, Y.-G. Microwave-Promoted Heck Reaction Using Pd(OAc)2 as Catalyst under Ligand-Free and Solvent-Free Conditions. Synth. Commun. 2007, 37, 217-222. [CrossRef]

24. Siamaki, A.R.; Khder, A.E.R.S.; Abdelsayed, V.; El-Shall, M.S.; Gupton, B.F. Microwave-assisted synthesis of palladium nanoparticles supported on graphene: A highly active and recyclable catalyst for carbon-carbon cross-coupling reactions. J. Catal. 2011, 279, 1-11. [CrossRef]

25. Cravotto, G.; Gaudino, E.C.; Tagliapietra, S.; Carnaroglio, D.; Procopio, A. A Green Approach to Heterogeneous Catalysis Using Ligand-Free, Metal-Loaded Cross-Linked Cyclodextrins. Green Process Synth. 2012, 1, 269-273. [CrossRef]

26. Baruah, D.; Das, R.N.; Hazarika, S.; Konwar, D. Biogenic synthesis of cellulose supported Pd(0) nanoparticles using hearth wood extract of Artocarpus lakoocha Roxb-A green, efficient and versatile catalyst for Suzuki and Heck coupling in water under microwave heating. Catal. Commun. 2015, 72, 73-80. [CrossRef]

27. Benyettou, F.; Motte, L.; Traboulsi, H.; Mazher, J.; Pasricha, R.; Olsen, J.-C.; Trabolsi, A.; Guenin, E. Palladium-Loaded Cucurbit[7]uril-Modified Iron Oxide Nanoparticles for C-C Cross-Coupling Reactions. Chem. Eur. J. 2018, 24, 2349-2353. [CrossRef] [PubMed]

28. Kyne, S.H.; Camp, J.E. Use of Monosaccharides in Metal-Catalyzed Coupling Reactions. ACS Sustain. Chem. Eng. 2017, 5, 41-48. [CrossRef]

29. Jha, A.K.; Shahni, R.K.; Jain, N. D-Glucosamine as a Green Ligand for Palladium-Catalyzed Cross-Coupling of Aryl and Heteroaryl Halides. Synlett 2015, 26, 259-264. [CrossRef]

30. Lindh, J.; Enquist, P.-A.; Pilotti, Å.; Nilsson, P.; Larhed, M. Efficient Palladium(II) Catalysis under Air. Base-Free Oxidative Heck Reactions at Room Temperature or with Microwave Heating. J. Org. Chem. 2007, 72, 7957-7962. [CrossRef]

31. Rudzinski, D.M.; Leadbeater, N.E. Microwave heating and conventionally heated continuous-flow processing as tools for performing cleaner palladium-catalyzed decarboxylative couplings using oxygen as the oxidant-A proof of principle study. Green Process Synth. 2013, 2, 323-328. [CrossRef]

32. Wang, D.; Gao, S. Sonogashira coupling in natural product synthesis. Org. Chem. Front. 2014, 1, 556-566. [CrossRef]

33. Chinchilla, R.; Nájera, C. Recent advances in Sonogashira reactions. Chem. Soc. Rev. 2011, 40, 5084-5121. [CrossRef] [PubMed]

34. Karak, M.; Barbosa, L.C.A.; Hargadenc, G.C. Recent mechanistic developments and next generation catalysts for the Sonogashira coupling reaction. RSC Adv. 2014, 4, 53442-53466. [CrossRef]

35. Chen, Y.; Markina, N.A.; Larock, R.C. An efficient, microwave-assisted, one-pot synthesis of indoles under Sonogashira conditions. Tetrahedron 2009, 65, 8908-8915. [CrossRef] [PubMed]

36. Conreaux, D.; Delaunay, T.; Desbordes, P.; Monteiro, N.; Balme, G. A convenient access to furo[3,2-c]pyridin-6(5H)-ones by the reaction of 5-iodo-4-methoxy-2-pyridones with terminal alkynes under microwave-enhanced Sonogashira conditions. Tetrahedron Lett. 2009, 50, 3299-3301. [CrossRef]

37. Puechmongkol, S.; Paosawatyanyong, B.; Bhanthumnavin, W. Environmentally benign microwave-assisted Sonogashira preparation of aromatic compounds. Mater. Sci. Forum 2011, 695, 113-116. [CrossRef] 
38. Olivier, J.-H.; Camerel, F.; Ziessel, R.; Retailleau, P.; Amadouc, J.; Pham-Huu, C. Microwave-promoted hydrogenation and alkynylation reactions with palladium-loaded multi-walled carbon nanotubesw. New J. Chem. 2008, 32, 920-924. [CrossRef]

39. Lee, M.; Kim, B.-H.; Lee, Y.; Kim, B.-T.; Park, J.B. Synthesis and Characterization of Graphene and Graphene Oxide Based Palladium Nanocomposites and Their Catalytic Applications in Carbon-Carbon Cross-Coupling Reactions. Bull. Korean Chem. Soc. 2014, 35, 1979-1985. [CrossRef]

40. Sedelmeier, J.; Ley, S.V.; Lange, H.; Baxendale, I.R. Pd-EnCat ${ }^{\mathrm{TM}} \mathrm{TPP} 30$ as a Catalyst for the Generation of Highly Functionalized Aryl- and Alkenyl-Substituted Acetylenes via Microwave-Assisted Sonogashira Type Reactions. Eur. J. Org. Chem. 2009, 4412-4420. [CrossRef]

41. Chang, W.; Shin, J.; Chae, G.; Jang, S.R.; Ahn, B.J. Microwave-assisted Sonogashira cross-coupling reaction catalyzed by Pd-MCM-41 under solvent-free conditions. J. Ind. Eng. Chem. 2013, 19, 739-743. [CrossRef]

42. Joy, M.N.; Bodke, Y.D.; Khader, K.K.A.; Sajith, A.M. A rapid approach for the copper, amine, and ligand-free Sonogashira coupling of 4-methyl-7-nonafluorobutylsulfonyloxy coumarins under microwave irradiation. Tetrahedron Lett. 2014, 55, 2355-2361. [CrossRef]

43. Lei, Y.; Hu, T.; Wu, X.; Wu, Y.; Xiang, H.; Sun, H.; You, Q.; Zhang, X. Microwave-assisted copper- and palladium-catalyzed sonogashira-type coupling of aryl bromides and iodides with trimethylsilylacetylene. Tetrahedron Lett. 2016, 57, 1100-1103. [CrossRef]

44. Hajipour, A.R.; Rafiee, F. Microwave-assisted Sonogashira cross-coupling reaction catalyzed by CN-ortho-palladated complex of tribenzylamine under copper-free conditions. J. Iran Chem. Soc. 2015, 12, 1163-1169. [CrossRef]

45. Küçükbay, H.; Yilmaz, Ü.; Yavuz, K.; Buĝday, N. Synthesis, characterization, and microwave-assisted catalytic activity in Heck, Suzuki, Sonogashira, and Buchwald \{Hartwig cross-coupling reactions of novel benzimidazole salts bearing N-phthalimidoethyl and benzyl moieties. Turk. J. Chem. 2015, 39, 1265-1278. [CrossRef]

46. Shah, D.; Kaur, H. Supported palladium nanoparticles: A general sustainable catalyst formicrowave enhanced carbon-carbon coupling reactions. J. Mol. Catal. A Chem. 2016, 424, 171-180. [CrossRef]

47. Biffis, A.; Centomo, P.; Del Zotto, A.; Zecca, M. Pd Metal Catalysts for Cross-Couplings and Related Reactions in the 21st Century: A Critical Review. Chem. Rev. 2018, 118, 2249-2295. [CrossRef] [PubMed]

48. Gazvoda, M.; Virant, M.; Pinter, B.; Košmrlj, J. Mechanism of copper-free Sonogashira reaction operates through palladium-palladium transmetallation. Nat. Commun. 2018, 9, 4814. [CrossRef]

49. Martina, K.; Manzoli, M.; Gaudino, E.C.; Cravotto, G. Eco-Friendly Physical Activation Methods for Suzuki-Miyaura Reactions. Catalysts 2017, 7, 98. [CrossRef]

50. Grushin, V.V.; Alper, H. Transformations of Chloroarenes, Catalyzed by Transition-Metal Complexes. Chem. Rev. 1994, 94, 1047-1062. [CrossRef]

51. Braga, A.A.; Ujaque, G.; Maseras, F. Mechanism of Palladium-Catalyzed Cross-Coupling Reactions. In Computational Modeling for Homogeneous and Enzymatic Catalysis; Morokuma, K., Musaev, D.G., Eds.; Wiley-VCH Verlag GmbH \& Co. KGaA: Weinheim, Germany, 2008; pp. 109-130. [CrossRef]

52. Blettner, C.G.; König, W.A.; Stenzel, W.; Schotten, T. Microwave-Assisted Aqueous Suzuki Cross-Coupling Reactions. J. Org. Chem. 1999, 64, 3885-3890. [CrossRef]

53. Leadbeater, N.E.; Marco, M. Fast, easy, clean chemistry by using water as a solvent and microwave heating: the Suzuki coupling as an illustration. J. Org. Chem. 2003, 68, 888-892. [CrossRef]

54. Poondra, R.R.; Fischer, P.M.; Turner, N.J. Efficient Palladium-Catalyzed Cross-Coupling of â-Chloroalkylidene/arylidene Malonates Using Microwave Chemistry. J. Org. Chem. 2004, 69, 6920-6922. [CrossRef] [PubMed]

55. Zhu, R.; Qu, F.; Quéléver, G.; Peng, L. Direct synthesis of 5-aryltriazole acyclonucleosides via Suzuki coupling in aqueous solution. Tetrahedron Lett. 2007, 48, 2389-2393. [CrossRef]

56. Nun, P.; Martinez, J.; Lamaty, F. Solvent-Free Microwave-Assisted Suzuki-Miyaura Coupling Catalyzed by PEPPSI-iPr. Synlett 2009, 11, 1761-1764. [CrossRef]

57. Leadbeater, N.E.; Williams, V.A.; Barnard, T.M.; Collins, M.J., Jr. Open-Vessel Microwave-Promoted Suzuki Reactions Using Low Levels of Palladium Catalyst: Optimization and Scale-Up. Org. Process Res. Dev. 2006, 10, 833-837. [CrossRef]

58. Freitag, J.; Hermann, M.; Nüchter, M.; Ondruschka, B.; Schneider, F.; Stolle, A. Microwave assisted synthesis using catalysts on controlled pore glass carriers. Opt. Appl. 2005, 35, 745-752. 
59. Worm-Leonhard, K.; Meldal, M. Green Catalysts: Solid-Phase Peptide Carbene Ligands in Aqueous Transition-Metal Catalysis. Eur. J. Org. Chem. 2008, 5244-5253. [CrossRef]

60. Kabalka, G.W.; Pagni, R.M.; Wang, L.; Namboodiri, V.; Hair, C.M. Microwave-assisted, solventless Suzuki coupling reactions on palladium-doped alumina. Green Chem. 2000, 2, 120-122. [CrossRef]

61. Kabalka, G.W.; Wang, L.; Pagni, R.M.; Hair, C.M.; Namboodiri, V. Solventless Suzuki Coupling Reactions On Palladium-Doped Potassium Fluoride Alumina. Synthesis 2003, 2, 217-222. [CrossRef]

62. Irfan, M.; Fuchs, M.; Glasnov, T.N.; Kappe, C.O. Microwave-Assisted Cross-Coupling and Hydrogenation Chemistry by Using Heterogeneous Transition-Metal Catalysts: An Evaluation of the Role of Selective Catalyst Heating. Chem. Eur. J. 2009, 15, 11608-11618. [CrossRef]

63. Arvela, R.K.; Leadbeater, N.E. Suzuki Coupling of Aryl Chlorides with Phenylboronic Acid in Water, Using Microwave Heating with Simultaneous Cooling. Org. Lett. 2005, 7, 2101-2104. [CrossRef]

64. Baxendale, I.R.; Griffiths-Jones, C.M.; Ley, S.V.; Tranmer, G.K. Microwave-Assisted Suzuki Coupling Reactions with an Encapsulated Palladium Catalyst for Batch and Continuous-Flow Transformations. Chem. Eur. J. 2006, 12, 4407-4416. [CrossRef] [PubMed]

65. Cannalire, R.; Tiecco, M.; Cecchetti, V.; Germani, R.; Manfroni, G. Advantageous Use of Ionic Liquids for the Synthesis of Pharmaceutically Relevant Quinolones. Eur. J. Org. Chem. 2018, 2977-2983. [CrossRef]

66. Li, L.; Sheng-hai, L.; Ri-hua, J. Microwave-assisted Palladium-micelle-catalyzed Suzuki Cross-coupling Reaction in Water. Chem. Res. Chin. Univ. 2011, 27, 589-591.

67. Camp, J.E.; Dunsford, J.J.; Cannons, E.P.; Restorick, W.J.; Gadzhieva, A.; Fay, M.W.; Smith, R.J. Glucose-Derived Palladium(0) Nanoparticles as in Situ-Formed Catalysts for Suzuki-Miyaura Cross-Coupling Reactions in Isopropanol. ACS Sustain. Chem. Eng. 2014, 2, 500-505. [CrossRef]

68. Pan, D.; Wu, A.; Li, P.; Xu, H.; Lei, F.; Shen, L. Palladium-loaded renewable polymer as a green heterogeneous catalyst for cross-coupling reactions under microwave irradiation. J. Chem. Res. 2014, 38, 715-718. [CrossRef]

69. Massaro, M.; Riela, S.; Cavallaro, G.; Gruttadauria, M.; Milioto, S.; Noto, R.; Lazzara, G. Eco-friendly functionalization of natural halloysite clay nanotube with ionic liquids by microwave irradiation for Suzuki coupling reaction. J. Organomet. Chem. 2014, 749, 410-415. [CrossRef]

70. Massaro, M.; Riela, S.; Lazzara, G.; Gruttadauria, M.; Milioto, S.; Noto, R. Green conditions for the Suzuki reaction using microwave irradiation and a new HNT-supported ionic liquid-like phase (HNT-SILLP) catalyst. Appl. Organometal. Chem. 2014, 28, 234-238. [CrossRef]

71. Massaro, M.; Riela, S.; Cavallaro, G.; Colletti, C.G.; Milioto, S.; Noto, R.; Parisi, F.; Lazzara, G. Palladium supported on Halloysite-triazolium salts as catalyst for ligand free Suzuki cross-coupling in water under microwave irradiation. J. Mol. Catal. A Chem. 2015, 408, 12-19. [CrossRef]

72. Baran, T.; Inanan, T.; Menteş, A. Synthesis, characterization, and catalytic activity in Suzuki couplingand catalase-like reactions of new chitosan supported Pd catalyst. Carbohydr. Polym. 2016, 145, 20-29. [CrossRef] [PubMed]

73. Baran, T.; Sargin, I.; Kaya, M.; Menteş, A. An environmental catalyst derived from biological waste materials forgreen synthesis of biaryls via Suzuki coupling reactions. J. Mol. Catal. A Chem. 2016, 420, $216-221$. [CrossRef]

74. Baran, T.; Sargin, I.; Kaya, M.; Menteş, A.; Ceter, T. Design and application of sporopollenin microcapsule supported palladium catalyst: Remarkably high turnover frequency and reusability in catalysis of biaryls. J. Colloid Interface Sci. 2017, 486, 194-203. [CrossRef] [PubMed]

75. Baran, N.Y.; Baran, T.; Menteş, A. Production of novel palladium nanocatalyst stabilized with sustainable chitosan/cellulose composite and its catalytic performance in Suzuki-Miyaura coupling reactions. Carbohydr. Polym. 2018, 181, 596-604. [CrossRef] [PubMed]

76. Ashok, D.; Lakshmi, B.V.; Sarasija, M. An Efficient Microwave-Assisted Suzuki Cross-Coupling on Coumarin Derivatives in Water and Evaluation of Antimicrobial Activity. Lett. Org. Chem. 2016, 13, 76-84. [CrossRef]

77. Leist, M.; Kerner, C.; Ghoochany, L.T.; Farsadpour, S.; Fizia, A.; Neu, J.P.; Schön, F.; Sun, Y.; Oelkers, B.; Lang, J.; et al. Roll-over cyclometalation: A versatile tool to enhance the catalytic activity of transition metal complexes. J. Organomet. Chem. 2018, 863, 30-43. [CrossRef]

78. Savitha, B.; Sajith, A.M.; Reddy, E.K.; Kumar, C.S.A.; Padusha, M.S.A. Suzuki-Miyaura cross-coupling reaction in water: Facile synthesis of (hetero) aryl uracil bases using potassiumorganotrifluoroborates under microwave irradiation. ChemistrySelect 2016, 1, 4721-4725. [CrossRef] 
79. Gayakhe, V.; Ardhapure, A.; Kapdi, A.R.; Sanghvi, Y.S.; Serrano, J.L.; García, L.; Pérez, J.; García, J.; Sánchez, G.; Fischer, C.; et al. Water-Soluble Pd-Imidate Complexes: Broadly Applicable Catalysts for the Synthesis of Chemically Modified Nucleosides via Pd-Catalyzed Cross-Coupling. J. Org. Chem. 2016, 81, 2713-2729. [CrossRef] [PubMed]

80. Bai, L.; Wang, J.-X. Reusable, Polymer-Supported, Palladium-Catalyzed, Atom-Efficient Coupling Reaction of Aryl Halides with Sodium Tetraphenylborate in Water by Focused Microwave Irradiation. Adv. Synth. Catal. 2008, 350, 315-320. [CrossRef]

81. Bai, L. Atom-efficient coupling reaction of aryl bromides with sodium tetraphenylborate catalyzed by reusable $\mathrm{Pd} / \mathrm{C}$ in water under focused microwave irradiation. Chin. Chem. Lett. 2009, 20, 158-160. [CrossRef]

82. Lee, J.-H.; Park, S.Y.; Park, A.; Yum, E.K. Diversification of Imidazo[1,2-a]pyridines under Microwave-Assisted Palladium-Catalyzed Suzuki Reaction. J. Korean Chem. Soc. 2017, 61, 299-303. [CrossRef]

83. Sharma, M.; Sharma, M.; Hazarika, A.; Satyanarayana, L.; Karunakar, G.V.; Bania, K.K. C-Cl bond activation with $\mathrm{Pd}(\mathrm{II})-\mathrm{NiO}$ nanoparticles supported on zeolite-Y: The role of charge transfer transition. Mol. Catal. 2017, 432, 210-219. [CrossRef]

84. Elazab, H.A.; Sadek, M.A.; El-Idreesy, T.T. Microwave-assisted synthesis of palladium nanoparticles supported on copper oxide in aqueous medium as an efficient catalyst for Suzuki cross-coupling reaction. Adsorpt. Sci. Technol. 2018, 36, 1352-1365. [CrossRef]

85. Şengül, A.; Hanhan, M.E. Water Soluble Benzimidazole Containing Ionic Palladium(II) Complex for Rapid Microwave-Assisted Suzuki Reaction of Aryl Chlorides. Appl. Organometal. Chem. 2018, 32, e4288. [CrossRef]

86. Tairai, A.; Sarmah, C.; Das, P. A highly efficient catalytic system for microwave-assisted Suzuki-Miyaura reactions as well as room temperature homocoupling reactions of arylboronic acids in aqueous media. Indian J. Chem. 2012, 51B, 843-848.

87. Dawood, K.M.; Shaaban, M.R.; Elamin, M.B.; Farag, A.M. Catalytic activity of some oxime-based $\mathrm{Pd}(\mathrm{II})$-complexes in Suzuki coupling of aryl and heteroaryl bromides in water. Arabian J. Chem. 2017, 10, 473-479. [CrossRef]

88. Baran, T.; Baran, N.Y.; Menteş, A. A new air and moisture stable robust bio-polymer based palladium catalyst for highly efficient synthesis of biaryls compounds. Appl. Organometal. Chem. 2018, 32, e4076. [CrossRef]

89. Cordovilla, C.; Bartolomé, C.; Martínez-Ilarduya, J.M.; Espinet, P. The Stille Reaction, 38 Years Later. ACS Catal. 2015, 5, 3040-3053. [CrossRef]

90. Barłóg, M.; Zhang, X.; Kulai, I.; Yang, D.S.; Sredojevic, D.N.; Sil, A.; Ji, X.; Salih, K.S.M.; Bazzi, H.S.; Bronstein, H.; et al. Indacenodithiazole-Ladder-Type Bridged Di(thiophene)-Difluoro-Benzothiadiazole-Conjugated Copolymers as Ambipolar Organic Field-Effect Transistors. Chem. Mater. 2019, 31, 9488-9496. [CrossRef]

91. Maleczka, R.E., Jr.; Lavis, J.M.; Clark, D.H.; Gallagher, W.P. Microwave-Assisted One-Pot Hydrostannylation/Stille Couplings. Org. Lett. 2000, 2, 3655-3658. [CrossRef]

92. Tan, X.; Zhou, Z.J.; Zhang, J.X.; Duan, X.H. Efficient One-Pot Cross-Coupling of Two Aryl Halides by Stannylation/Stille Reaction in Water under Microwave Irradiation. Eur. J. Org. Chem. 2014, 5153-5157. [CrossRef]

93. Appukkuttan, P.; Dehaen, W.; Van der Eycken, E. Suzuki-Miyaura and Stille Reactions as Key Steps in the Synthesis of Diversely Functionalized Amaryllidaceae Alkaloid Analogs Bearing a 5,6,7,8-Tetrahydrobenzo [c,e] Azocine Skeleton. Comb. Chem. High Throughput Screen. 2007, 10, 790-801. [CrossRef]

94. Cebrián, C.; De Cózar, A.; Prieto, P.; Díaz-Ortiz, A.; De la Hoz, A.; Carrillo, J.R.; Rodriguez, A.M.; Montilla, F. Microwave-Assisted Stille Reactions as a Powerful Tool for Building Polyheteroaryl Systems Bearing a (1H)-1,2,4-Triazole Moiety. Synlett 2010, 55-60. [CrossRef]

95. Susanto, W.; Chu, C.-Y.; Ang, W.J.; Chou, T.-C.; Lo, L.-C.; Lam, Y. Fluorous Oxime Palladacycle: A Precatalyst for Carbon-Carbon Coupling Reactions in Aqueous and Organic Medium. J. Org. Chem. 2012, 77, 2729-2742. [CrossRef] [PubMed]

96. Hajipour, A.R.; Karamia, K.; Rafiee, F. An efficient Stille cross-coupling reaction catalyzed by ortho-palladated complex of tribenzylamine under microwave irradiation. Appl. Organometal. Chem. 2012, 26, 27-31. [CrossRef]

97. Xu, G.; Zhang, Y.; Wang, K.; Fu, Y.; Du, Z. Microwave-assisted Stille cross-coupling reaction catalysed by in situ formed palladium nanoparticles. J. Chem. Res. 2015, 39, 399-402. [CrossRef] 
98. Öhberg, L.; Westman, J. One-pot Three-step Solution Phase Syntheses of Thiohydantoins using Microwave Heating. Synlett 2001, 1893-1896. [CrossRef]

99. Stanetty, P.; Schnürch, M.; Mihovilovic, M.D. Synthesis of Pyridinyl-Pyrimidines via Pd-Catalyzed Cross-Coupling Reactions: A Comparison of Classical Thermal and Microwave Assisted Reaction Conditions. Synlett 2003, 1862-1864. [CrossRef]

100. Walla, P.; Kappe, C.O. Microwave-assisted Negishi and Kumada cross-coupling reactions of aryl chlorides. Chem. Commun. 2004, 564-565. [CrossRef]

101. Mutule, I.; Suna, E. Arylzinc species by microwave assisted Grignard formation-transmetallation sequence: application in the Negishi coupling. Tetrahedron 2005, 61, 11168-11176. [CrossRef]

102. Genov, M.; Almorín, A.; Espinet, P. Microwave assisted asymmetric Suzuki-Miyaura and Negishi cross-coupling reactions: Synthesis of chiral binaphthalenes. Tetrahedron Asymmetry 2007, 18, 625-627. [CrossRef]

103. Motwani, H.V.; Larhed, M. Diarylated Ethanones from Mo(CO)6-Mediated and Microwave-Assisted Palladium-Catalysed Carbonylative Negishi Cross-Couplings. Eur. J. Org. Chem. 2013, 4729-4733. [CrossRef]

104. Foubelo, F.; Nájera, C.; Yus, M. The Hiyama Cross-Coupling Reaction: New Discoveries. Chem. Rec. 2016, 16, 2521-2533. [CrossRef] [PubMed]

105. Clarke, M.L. First Microwave-Accelerated Hiyama Coupling of Aryl- and Vinylsiloxane Derivatives: Clean Cross-Coupling of Aryl Chlorides within Minutes. Adv. Synth. Catal. 2005, 347, 303-307. [CrossRef]

106. Peñafiel, I.; Pastor, I.M.; Yus, M.; Esteruelas, M.A.; Oliván, M.; Oñate, E. (NHC)Palladium Complexes from Hydroxy-Functionalized Imidazolium Salts as Catalyst for the Microwave-Accelerated Fluorine-Free Hiyama Reaction. Eur. J. Org. Chem. 2011, 7174-7181. [CrossRef]

107. Hajipour, A.R.; Rafiee, F. Microwave-assisted Stille and Hiyama cross-coupling reactions catalyzed by ortho-palladated complexes of homoveratrylamine. Tetrahedron Lett. 2012, 53, 4661-4664. [CrossRef]

108. Hajipour, A.R.; Rafiee, F.; Najafi, N. Hiyama cross-coupling reaction catalyzed by a palladium salt of 1-benzyl-4-aza-1-azoniabicyclo [2.2.2]octane chloride under microwave irradiation. Appl. Organometal. Chem. 2014, 28, 217-220. [CrossRef]

109. Martínez, R.; Pastor, I.M.; Yus, M. 1,2-Functionalized Imidazoles as Palladium Ligands: An Efficient and Robust Catalytic System for the Fluorine-Free Hiyama Reaction. Eur. J. Org. Chem. 2014, 872-877. [CrossRef]

110. Shah, D.; Kaur, H. Microwave Assisted Fluoride-Free Hiyama Cross-Coupling Reaction Catalyzed by Pd (0)-PVP Nanoparticles. Curr. Catal. 2014, 3, 39-46. [CrossRef]

111. Liebeskind, L.S.; Srogl, J. Thiol Ester-Boronic Acid Coupling. A Mechanistically Unprecedented and General Ketone Synthesis. J. Am. Chem. Soc. 2000, 122, 11260-11261. [CrossRef]

112. Prokopcová, H.; Kappe, C. The Liebeskind-Srogl C-C Cross-Coupling Reaction. Angew. Chem. Int. Ed. 2009, 48, 2276-2286. [CrossRef]

113. Cheng, H.-G.; Chen, H.; Liu, Y.; Zhou, Q. The Liebeskind-Srogl Cross-Coupling Reaction and its Synthetic Applications. Asian J. Org. Chem. 2018, 7, 490-508. [CrossRef]

114. Lengar, A.; Kappe, C.O. Tunable Carbon-Carbon and Carbon-Sulfur Cross-Coupling of Boronic Acids with 3,4-Dihydropyrimidine-2-thiones. Org. Lett. 2004, 6, 771-774. [CrossRef] [PubMed]

115. Prpkopcová, H.; Pisani, L.; Kappe, C.O. Synthesis of 5-Aroyldihydropyrimidinones via Liebeskind-Srogl Thiol Ester-Boronic Acid Cross-Coupling. Synlett 2007, 43-46. [CrossRef]

116. Pisani, L.; Prpkopcová, H.; Kremsner, J.M.; Kappe, C.O. 5-Aroyl-3,4-dihydropyrimidin-2-one Library Generation via Automated Sequential and Parallel Microwave-assisted Synthesis Techniques. J. Comb. Chem. 2007, 9, 415-421. [CrossRef] [PubMed]

117. Čerňová, M.; Pohl, R.; Klepetářová, B.; Hocek, M. A General Regioselective Synthesis of 2,4-Diarylpyrimidines from 2-Thiouracil through Two Orthogonal Cross-Coupling Reactions. Synlett 2012, 23, 1305-1308. [CrossRef]

118. Krömer, M.; Klečka, M.; Slavětínská, L.; Klepetářová, B.; Hocek, M. Chemoselective Synthesis of 4,5-Diarylpyrrolo [2,3-d] pyrimidines (6,7-Diaryl-7-deazapurines) by Consecutive Suzuki and Liebeskind-Srogl Cross-Couplings. Eur. J. Org. Chem. 2014, 7203-7210. [CrossRef]

119. Mehta, V.P.; Sharma, A.; Van der Eycken, E. The First Palladium-Catalyzed Desulfitative Sonogashira-Type Cross-Coupling of (Hetero)aryl Thioethers with Terminal Alkynes. Org. Lett. 2008, 10, 1147-1150. [CrossRef]

120. Modha, S.G.; Trivedi, J.C.; Mehta, V.P.; Ermolat'ev, D.S.; Van der Eycken, E.V. An Expeditious Route toward Pyrazine-Containing Nucleoside Analogues. J. Org. Chem. 2011, 76, 846-856. [CrossRef] 
121. Shook, B.C.; Chakravarty, D.; Jackson, P.F. Microwave-assisted Sonogashira-type cross couplings of various heterocyclic Methylthioethers. Tetrahedron Lett. 2009, 50, 1013-1015. [CrossRef]

122. Prieur, V.; Pujol, M.D.; Guillaumet, G. A Strategy for the Triarylation of Pyrrolopyrimidines by Using Microwave-Promoted Cross-Coupling Reactions. Eur. J. Org. Chem. 2015, 6547-6556. [CrossRef]

123. Liu, Z.; Thacker, S.G.; Fernandez-Castillejo, S.; Neufeld, E.B.; Remaley, A.T.; Bittman, R. Synthesis of Cholesterol Analogues Bearing BODIPY Fluorophores by Suzuki or Liebeskind-Srogl Cross-Coupling and Evaluation of Their Potential for Visualization of Cholesterol Pools. ChemBioChem 2014, 15, 2087-2096. [CrossRef]

124. Ho, T.C.; Shimada, N.; Tius, M.A.; Nikas, S.P.; Zhang, W. C1'-Azacycloalkyl Hexahydrocannabinols. J. Org. Chem. 2017, 82, 7839-7849. [CrossRef]

125. Maltsev, O.V.; Pothig, A.; Hintermann, L. Synthesis of Soai Aldehydes for Asymmetric Autocatalysis by Desulfurative Cross-Coupling. Org. Lett. 2014, 16, 1282-1285. [CrossRef]

126. Maltsev, O.V.; Rausch, R.; Quan, Z.-J.; Hintermann, L. Synthesis of Soai Type 2-Arylpyrimidine-5-carbaldehydes through Desulfurative Cross-Coupling with Arylboronic Acids. Eur. J. Org. Chem. 2014, 7426-7432. [CrossRef]

127. Himmelspach, A.; Reiss, G.J.; Finze, M. Microwave-Assisted Kumada-Type Cross-Coupling Reactions of Iodinated Carba-Closo-Dodecaborate Anions. Inorg. Chem. 2012, 51, 2679-2688. [CrossRef] [PubMed]

128. Rodríguez, N.; Gooßen, L.J. Decarboxylative Coupling Reactions: A Modern Strategy for C-C-Bond Formation. Chem. Soc. Rev. 2011, 40, 5030-5048. [CrossRef] [PubMed]

129. Gooßen, L.J.; Zimmermann, B.; Linder, C.; Rodríguez, N.; Lange, P.P.; Hartung, J. Synthesis of Biaryls and Aryl Ketones via Microwave-Assisted Decarboxylative Cross-Couplings. Adv. Synth. Catal. 2009, 351, 2667-2674. [CrossRef]

130. Gooßen, L.J.; Rodríguez, N.; Lange, P.P. Linder, C. Decarboxylative Cross-Coupling of Aryl Tosylates with Aromatic Carboxylate Salts. Angew. Chem. Int. Ed. 2010, 49, 1111-1114. [CrossRef]

131. Behrends, M.; Sävmarker, J.; Sjöberg, P.J.R.; Larhed, M. Microwave-Assisted Palladium(II)-Catalyzed Synthesis of Aryl Ketones from Aryl Sulfinates and Direct ESI-MS Studies Thereof. ACS Catal. 2011, 1, 1455-1459. [CrossRef]

132. Cazorla, C.; Billamboz, M.; Chevrin-Villette, C.; Hapiot, F.; Monflier, E.; Len, C. Conjugated Dienyl Derivatives by Green Bisallylic Substitution: Synthetic and Mechanistic Insight. ChemCatChem 2016, 8 , 2321-2328. [CrossRef]

133. Arvela, R.K.; Leadbeater, N.E.; Sangi, M.S.; Williams, V.A.; Granados, P.; Singer, R.D. A Reassessment of the Transition-Metal Free Suzuki-Type Coupling Methodology. J. Org. Chem. 2005, 70, 161-168. [CrossRef] 